\title{
Article \\ Impact Analysis of Initial Cracks' Angle on Fatigue Failure of Flange Shafts
}

\author{
Zhiqiang Xu ${ }^{1,2}$, Yunxian Cui ${ }^{1}{ }^{1}$, Baoliang $\mathrm{Li}^{1}{ }^{1}$, Ketong Liu ${ }^{3}$, Feiting Shi ${ }^{4} \mathbb{D}$ and Peng Cao ${ }^{5, *}$ \\ 1 School of Mechanical Engineering, Dalian Jiaotong University, Dalian 116028, China; \\ xzq3171057@126.com (Z.X.); dlcyx007@126.com (Y.C.); libl@djtu.edu.cn (B.L.) \\ 2 School of Chemical and Mechanical Engineering, Eastern Liaoning University, Dandong 118001, China \\ 3 College of Architecture and Civil Engineering, Xi'an University of Science and Technology, \\ Xi'an 710054, China; ketong-1982@163.com \\ 4 School of Civil Engineering, Yancheng Institute of Technology, Yancheng 224051, China; shifeiting@ycit.cn \\ 5 College of Architecture and Civil Engineering, Beijing University of Technology, Beijing 100124, China \\ * Correspondence: caopeng518888@126.com
}

Citation: Xu, Z.; Cui, Y.; Li, B.; Liu, K.; Shi, F.; Cao, P. Impact Analysis of Initial Cracks' Angle on Fatigue Failure of Flange Shafts. Coatings 2022, 12, 276. https://doi.org/ 10.3390/coatings12020276

Academic Editor: Jian Chen

Received: 19 January 2022

Accepted: 14 February 2022

Published: 18 February 2022

Publisher's Note: MDPI stays neutral with regard to jurisdictional claims in published maps and institutional affiliations.

Copyright: (c) 2022 by the authors. Licensee MDPI, Basel, Switzerland. This article is an open access article distributed under the terms and conditions of the Creative Commons Attribution (CC BY) license (https:// creativecommons.org/licenses/by/ $4.0 /)$.

\begin{abstract}
A fatigue test on the failure mode of flange shafts was conducted. The propagation characteristics of the initial crack at the junction between the shaft and the flange as well as its angle effect were studied. This study developed an analysis program of fatigue crack propagation, based on the APDL (ANSYS Parametric Design Language). It obtained the effective angle interval within which the initial crack is able to propagate. The fitting calculation formula was derived and the results showed that: (1) The initial crack at the junction between the shaft and the flange would propagate in the radial and axial directions; the unstable crack propagation would cause an abrupt fracture of the cross-section, failing connection; and the angle of initial crack was uncertain. (2) The crack followed the I-II-III mixed mode, which was dominated by mode I. An initial crack with a larger angle showed more noticeable II-III characteristics; $K_{\mathrm{II}}$ and $K_{\mathrm{III}}$ affected the crack's propagation angle in the radial and axial directions and they also affected the structure's surface direction. (3) The deepest point A of the crack was located at the junction between the shaft and the flange. Its crack propagation can be divided into three stages: rapid growth (stage 1), steady decline (stage 2, buffer stage), and instability (stage 3). The initial crack angle not only affected the propagation rate at stage 1 but also influenced the fatigue life distribution of the structure during propagation. The larger the initial crack angle was, the smaller the proportion of buffer stage in the total fatigue life would be. Moreover, the propagation of crack with a larger initial angle reached instability faster after stage 1, which would cause an abrupt fracture of the cross-section. This was unfavorable for deciding the crack detection time or carrying out maintenance and reinforcement. (4) The crack propagation at the junction between the shaft and the flange was determined by the size relation between $\Delta K_{\mathrm{I}}$ and $\Delta K_{\mathrm{th}}$, instead of the effective stress intensity factor. The effective stress intensity factor can partly reflect the law of crack propagation, but cannot serve as the only criterion for crack propagation; it must be combined with the effective angle interval, which was negatively correlated with the crack's shape ratio, to determine whether the crack would propagate.
\end{abstract}

Keywords: flange shaft; fatigue failure; fracture mechanics; stress intensity factor; crack propagation

\section{Introduction}

As the support of the transmission parts, a flange shaft can transfer the torque and bear the load. It is widely used in machines and equipment, such as machine tools, aircraft engines, fans, and pumps. However, when it is under cyclic stress when working, it will be subject to fatigue cracks. Studies have shown that most flanges have fatigue cracks after 5-10 years of service [1]. Fatigue cracks are most common at the junction between the shaft and the flange. This is due to the abrupt change of the cross-section. Once the crack 
occurs, it will propagate in the radial and axial directions, seriously affecting the safety of machinery. Therefore, it is important to investigate the fatigue failure of flange shafts.

In the engineering field, the most common assessment method of fatigue life is the S-N curve nominal stress method. This method greatly simplifies the fatigue analysis and is easy to use. However, some obstacles remain: first, it needs to be checked whether the S-N curve of various weld details is suitable for new steel; secondly, making S-N curve requires previous load information to predict the fatigue life of the structure details, but the historic information is difficult to acquire, let alone determine the fatigue life; third, this method cannot assess the remaining life with the flange's test data, such as the distribution and size of the crack. In recent years, the method that combines fracture mechanics with finite elements has developed rapidly and become one of the main tools in the research of fatigue crack [2-7]. Atanasovska et al. carried out finite element analysis of corrosion fatigue crack and turbine shaft damage based on actual turbine shaft failure cases and proposed a new method to calculate the stress concentration coefficient [8]. Li et al. studied the effects of pre-strain on fatigue crack growth rate, strain energy, crack tip plastic zone size, and fatigue fracture mechanism of commercial titanium alloy (CP-Ti) under a wide range of load amplitude and load ratio, and analyzed how pre-strain affects fatigue crack growth and thus the entire fatigue life [9]. Sola et al. combined the critical plane fatigue theory and URM standard to preliminarily estimate the damage and fatigue life of a crankshaft with increasing power [10]. Pandey performed the analysis of the fracture on the crankshaft and predicted the crack propagation life based on the Pairs formula [11]. Lei used crack beam elements to simulate the failure diagnosis of crankshaft crack [12]. Zhou conducted a fatigue test of a flange shaft under bending stress and obtained the curve of the crack propagation rate and the residual strength model [13].

Currently, global studies on the cracks of mixed-mode mainly focus on cylindrical samples. Yang et al. conducted a series of fatigue tests on C45 steel specimens with local surface cracks and found that carburizing treatment can effectively delay crack propagation and improve the fatigue life of specimens. Surface depth can only improve the fatigue life of materials in a certain range, too much depth may reduce the fatigue strength of materials [14]. Ye et al. obtained the S-N curve of 7A85-T7452 aluminum alloy in air and neutral $3.5 \% \mathrm{NaCl}$ solution through axial fatigue test and found that corrosion had no obvious influence on fatigue life in high-stress cycling regions, but significant influence in low-stress regions [15]. Fonte designed and built the test machine of bending coupling fatigue and performed fatigue tests on the cylindrical samples [16-18]. The test showed that the crack propagation rate of the cylindrical samples decreased after the superposition of the steady-state torsion load. This was due to the crack closure. Yang carried out a crack propagation test on cylindrical samples under multiaxial load and showed that axial tension greatly affected the crack propagation rate, while axial pressure had no impact on the crack propagation rate [19]. Zangeneh simulated the failure of an agitator shaft in a large vessel with ABAQUS and found that the failure was due to the stress concentration at the root of the shaft [20]. Furthermore, the shape of crack morphology was compared with numerical and experimental results. Azevedo [21] claimed that rounding radius in the shaft base was the cause of failure employing finite element simulation of a sugarcane loader rear shaft. Aliakbari analyzed the failure of a ductile iron crankshaft in a compact pickup truck diesel engine and contributed its failure to the low cycle fatigue [22]. Khameneh focused on high-cycle bending fatigue in the crankshaft and revealed the failure mechanism from a micro perspective [23]. Alvarez et al. compared Tungsten Inert Gas Welded Alloy 718 and Laser Beam Welded Alloy 718 on hot cracking susceptibility by varestraint testing [24]. Coro et al. had proposed a new methodology to evaluate the reliability impact of the replacement of welded components using the first-order reliability method and fracture mechanics [25]. Rodriguez et al. studied the effect of roller burnishing on improving the fatigue performance of austempered iron casting cylindrical parts [26]. A new methodology to evaluate the reliability impact of the replacement of welded components using the firstorder reliability method and fracture mechanics was proposed. 
Many scholars have fully studied the propagation characteristics of fatigue cracks on welding components of shafts based on the numerical simulation of fracture mechanics [27]. However, the influence of initial fracture direction and size on the fracture initiation and propagation in flank shafts is rarely investigated, which can provide valuable insights into inspection, repair, and scrapping of flank shafts.

Due to the complexity and randomness during the casting, the initial crack on the flange shaft is unavoidable. There is a strong geometric uncertainty about the initial crack at the junction between the shaft and the flange, but it is hardly studied. Therefore, it becomes urgent to analyze the propagation characteristics of the fatigue crack on the flange shaft. Based on the theory of 3D fracture mechanics, the author studied the propagation characteristics of fatigue crack at the junction between shaft and flange and the focus of the study was on the impact of the initial crack angle. The study aims to help researchers understand more about the propagation characteristics of the fatigue crack on the flange shaft and to provide a reference for related research.

\section{Calculation Principle of Crack Propagation}

Flange shaft fatigue is typical high cycle fatigue, with the size of the plastic zone on the crack tip much smaller than the crack length and a linear elastic state. Therefore, the theory and method of linear elastic fracture mechanics can still solve the problem of the small-scale yield. This paper studied the 3D propagation of the fatigue crack based on linear elastic fracture mechanics.

\subsection{Criterion of the Crack Propagation Direction}

Based on different forms of load, a crack can have three basic modes: the opening mode (mode I), the sliding mode (mode II), and the tearing mode (mode III). As the flange shaft is subject to the common interaction of the bending moment, the axial force, and the shear force, most of its fatigue cracks are of a mixed-mode, deriving from the combination of two or three cracking modes. The mixed-mode cracks and opening mode cracks are different at the macroscopic level. One significant difference is that the mixedmode cracks do not necessarily propagate along the plane determined by the initial crack. Instead, the crack propagation will be at a certain angle of the original crack surface. The spatial form is determined jointly by the propagation step length and the propagation angle. Based on the maximum circumferential stress criterion [28], this paper assumed that the crack propagated along with the position of the maximum circumferential stress. The maximum circumferential stress was at the circular failure nuclear perimeter of the crack tip. The propagation angle of the crack surface is $\theta$ [29]:

$$
\theta=2 \arctan \left(\frac{1-\sqrt{1+8 K_{\mathrm{II}}^{2} / K_{\mathrm{I}}^{2}}}{4 K_{\mathrm{II}} / K_{\mathrm{I}}}\right)
$$

where: $K_{\mathrm{I}}$ and $K_{\mathrm{II}}$ were the stress intensity factors of modes I and II cracks, respectively.

\subsection{Effective Stress Intensity Factor}

In the mechanics of the linear elastic fracture, the stress intensity factor is an important physical quantity to measure the local stress-strain state of the crack tip. Accurate stress intensity factor at the crack tip is the premise to analyze the fatigue crack propagation and fatigue life. The fatigue crack starts at the junction between the shaft and the flange. As the crack is a mixed-mode (I-II-III), when calculating the fatigue using the stress intensity factor, the impact of various cracking modes on crack propagation should be considered. BS7910 uses Formula (2) to calculate the equivalent stress intensity factor amplitude of the mixed-mode crack [29]. The far-field force that drives crack propagation may be negative. Therefore, considering the possible crack closure effect, this paper used the effective stress 
intensity factor in Formula (3) instead of $\Delta K_{\mathrm{I}}$ in the Paris formula for the analysis of fatigue crack propagation and fatigue life.

$$
\begin{gathered}
\Delta K_{e q}=\sqrt{\Delta K_{\mathrm{I}}^{2}+\Delta K_{\mathrm{II}}^{2}+\alpha \Delta K_{\mathrm{III}}^{2} /(1-v)} \\
\Delta K_{e f f}= \begin{cases}0, & K_{e q, \max }<0 \\
\Delta K_{e q}, & K_{e q, \max } \geq 0\end{cases}
\end{gathered}
$$

where: $\Delta K_{e q}$ and $\Delta K_{e f f}$ were the amplitudes of equivalent stress intensity factor and effective stress intensity factor, respectively; $\Delta K_{\mathrm{I}}, \Delta K_{\mathrm{II}}$ and $\Delta K_{\mathrm{III}}$ were the amplitudes of stress intensity factor of modes I, II, and III cracks; $\Delta K_{\text {eq, } \max }$ was the maximum value of the equivalent stress intensity factor, $v$ was the Poisson's ratio and here we adopted 0.3 , and $\alpha$ was the weight coefficient, for which we took 1.0 for safety [30].

\subsection{Crack Propagation Analysis Model}

Based on the analysis of the fatigue crack propagation of metal structures, Paris et al. proposed a theoretical model to describe the relation between crack length and fatigue life in subcritical propagation areas [31]. For the propagation of mixed-mode fatigue crack, the Paris formula was modified by the amplitude of effective stress intensity factor to analyze the propagation of mixed-mode crack tip, as shown in Formula (4):

$$
\frac{d a}{d N}=C_{e q}\left(\Delta K_{e f f}\right)^{m}
$$

where: $d a / d N$ was the crack propagation rate, $a$ was the crack size, $N$ was the number of stress cycles, $C_{e q}$ and $m$ were the fatigue crack propagation parameters. The test showed that among the test specimens with the same geometry and material, the mixed loading modes had little effect on $m$, but the great effect on $C_{e q}$, as shown in Formula (5) [32]:

$$
C_{e q}=C\left[1+\beta\left(M^{e}-1\right)^{2}\right]
$$

where: $M^{e}=\frac{2}{\pi} \tan ^{-1}\left|\frac{K_{I}}{K_{I I}}\right|, C$ and $M$ were the Paris coefficients of the mode I crack; $\beta$ was the tested coefficient, in which we took $\beta=3$ for aluminum alloy and steel, as suggested by the test [30].

According to Formula (4), the $N$ (fatigue life) can be obtained by the integral Formula (6) with the given $a_{0}$ (initial crack depth), $a_{f}$ (final crack depth), and $\Delta K_{e f f}$.

$$
N=\int_{a_{0}}^{a_{f}} \frac{d a}{C_{e q}\left(\Delta K_{e f f}\right)^{m}}
$$

However, the stress distribution of complex structures is a complicated 3D problem. During the crack propagation, the stress is constantly redistributed, so it is difficult to express $\Delta K_{e f f}$. The Paris formula is an ordinary differential equation with an initial value, so integral Formula (6) can be converted to summation Formula (7). This can be done based on Euler's formula. Through iterative calculation, the final fatigue life is obtained:

$$
N_{n+1}=N_{n}+\frac{d a}{C_{e q}\left(\Delta K_{e f f}\right)^{m}}
$$

where: $N_{n+1}$ and $N_{n}$ were the fatigue life of the structure at No. $n+1$ and No. $n$ iterative steps, respectively.

Similarly, the expression for the iterative calculation of crack propagation was:

$$
a_{n+1}=a_{n}+\Delta N\left[C_{e q}\left(\Delta K_{e f f}\right)^{m}\right]
$$


where: $a_{n+1}$ and $a_{n}$ were the crack sizes at No. $n+1$ and No. $n$ iterative steps, respectively; $\Delta N$ was the cyclic stress increment applied from $a_{n}$ to $a_{n+1}$.

Formulas (7) and (8) reflected the numerical simulation of crack propagation and calculation of the structure's fatigue life.

\subsection{Calculation Procedures of the Crack Propagation Process}

For example, if $a_{0}$ (initial crack depth) and $c_{0}$ (initial crack length) were given, the propagation of an elliptical or semi-elliptical crack to limit $a_{c}$ or $c_{\mathcal{c}}$ can be simulated in the following steps:

(1) Select an appropriate crack propagation step length as $\Delta a_{i}$. Generally, the smaller $\Delta a_{i}$ is, the higher the calculation accuracy and the longer the calculation time will become.

(2) The figures to be calculated include: crack depth $a_{i}$, crack length $c_{i}$, the effective stress intensity factor $\Delta K_{e f f, i}^{(a)}$ of the deepest point of crack, crack depth $a_{i-1}$, crack length $c_{i-1}$, effective stress intensity factor $\Delta K_{\text {eff }, i}^{(a)}$ of the deepest point of crack, and the effective stress intensity factor $\Delta K_{e f f, i-1}^{(c)}$ of long axis endpoint of the crack. Among them, $i$ represents the number of steps for current propagation calculation, and $n$ refers to the total number of propagation steps calculation.

(3) With a given tolerance $\varepsilon$, if $\left(\Delta K_{e f f, i}^{(a)}-\Delta K_{e f f, i-1}^{(a)}\right) / \Delta K_{e f f, i-1}^{(a)}<\varepsilon$ reaches accuracy, then we proceed to the following steps, otherwise, let $\Delta a_{i}=\Delta a_{i} / 2$ and return to step (2).

(4) Suppose that the $\mathrm{d} a / \mathrm{dN}$ remained unchanged when the crack propagated from $a_{i-1}$ to $a_{i}$, and

$$
\mathrm{d} a / \mathrm{dN}=C_{e q}\left(\Delta K_{e f f, i-1}^{(a)}\right)^{m}
$$

Calculate the number of load cycles corresponding to $\Delta a_{i}$ :

$$
\Delta N_{i}=\Delta a_{i} /(\mathrm{d} a / \mathrm{dN})_{i}
$$

Then the cumulative number of load cycles corresponding to the crack depth $a_{i}$ is:

$$
N_{i}=\sum \Delta N_{i}
$$

(5) Calculate the propagation rate and propagation step length of the long axis endpoint of the crack in No. $i$ propagation:

$$
\begin{gathered}
\mathrm{d} c / \mathrm{dN}=C_{e q}\left(\Delta K_{e f f, i-1}^{(c)}\right)^{m} \\
\Delta c_{i}=\Delta N_{i} /(\mathrm{d} c / \mathrm{dN})_{i}
\end{gathered}
$$

(6) Repeat step (1)-step (5), until $a_{i}=a_{0}+\sum \Delta a_{i} \geq a_{c}$ or $c_{i}=c_{0}+\sum \Delta c_{i} \geq c_{\mathcal{c}}$.

The above steps can be implemented according to the programming in the program block diagram shown in Figure 1. 


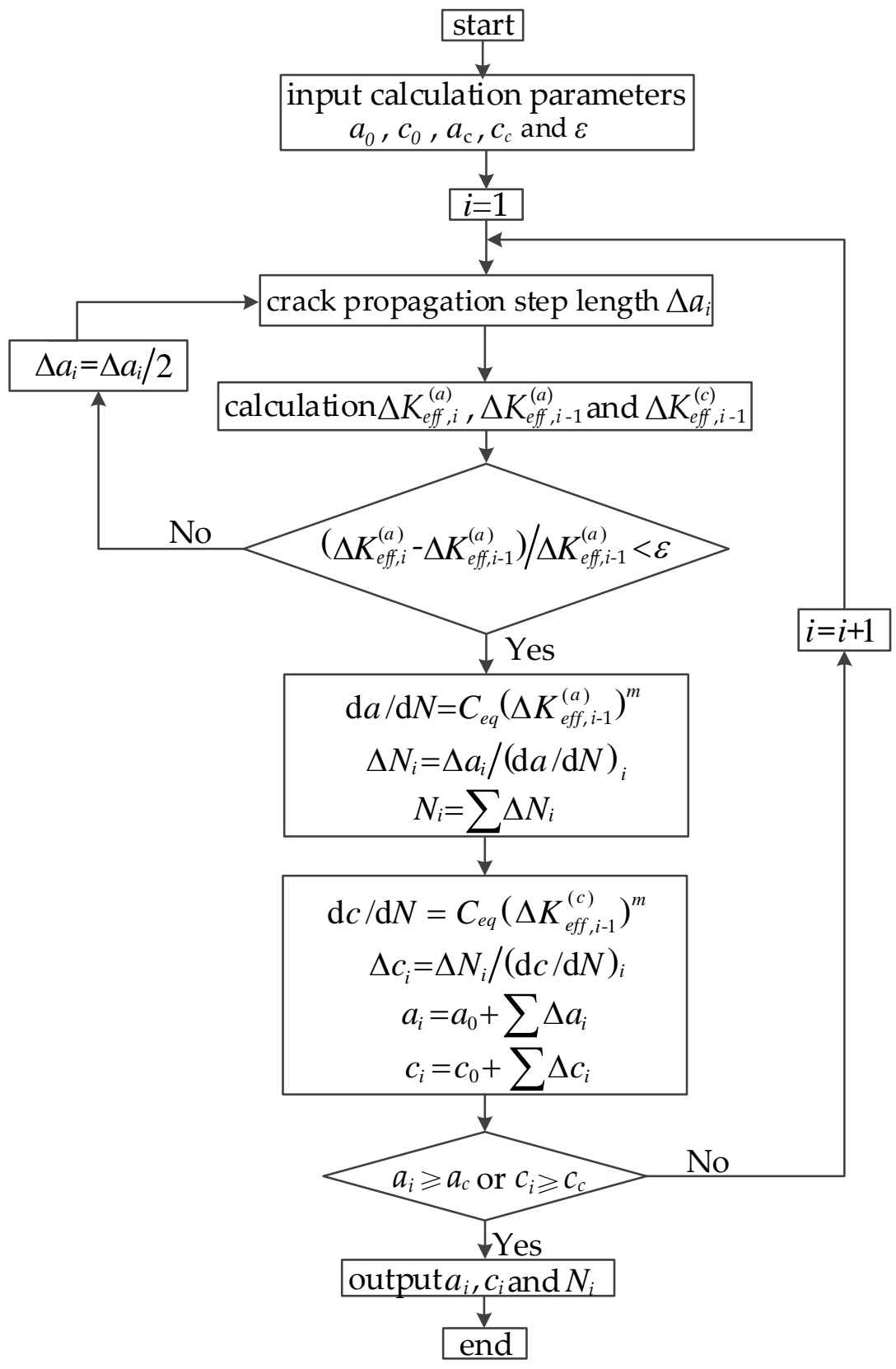

Figure 1. Calculation procedures of the crack propagation process.

\section{Verification of Fatigue Test and Numerical Simulation Method for Flange Shaft}

\subsection{Test Overview}

Considering the uncertainty of test results, three test specimens of the same size (T1, T2, and T3) were made. The specimens were of the same material, 45\# steel. The detailed size of test specimens, restraint loading device, welding form, and test site layout are shown in Figure 2. To investigate the fatigue cracking performance of the flange shaft, the load of the actuator passed through the clamp to the shaft. Near the upper edge of the junction, which was between the shaft and flange, was subjected to tensile and bending stress by acting the load imposed by the actuator. The test specimen was fixed on the platform by bolts, the flange shaft was connected with the actuator by a fixture in the course of experimental testing, then the actuator imposed a cyclic load on the flange shaft for fatigue test loading. Based on the static load test results, $11 \mathrm{kN}$ was taken as the maximum fatigue load, the stress ratio was 0.05 , and the frequency was $2 \mathrm{~Hz}$. 

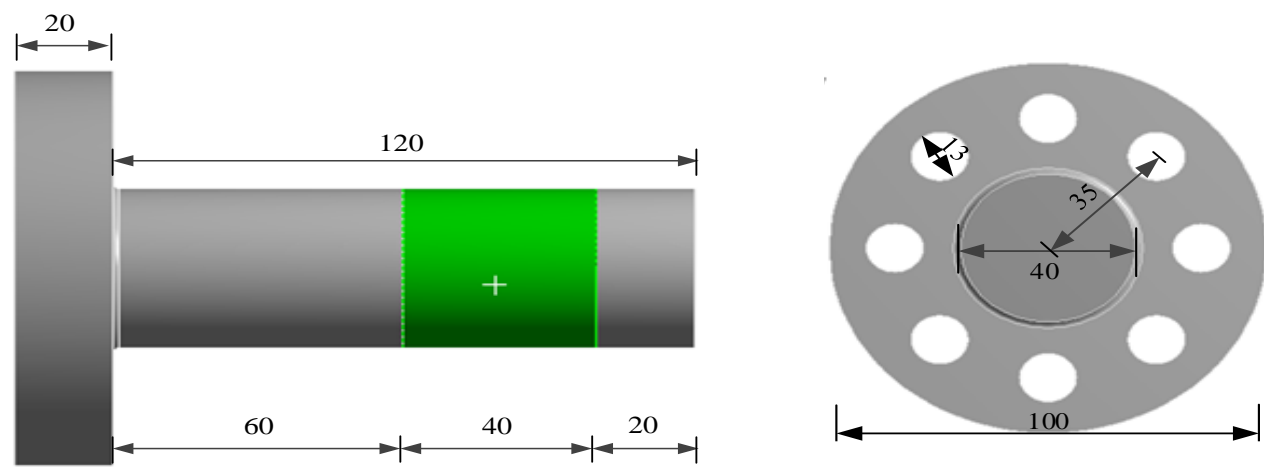

(a)
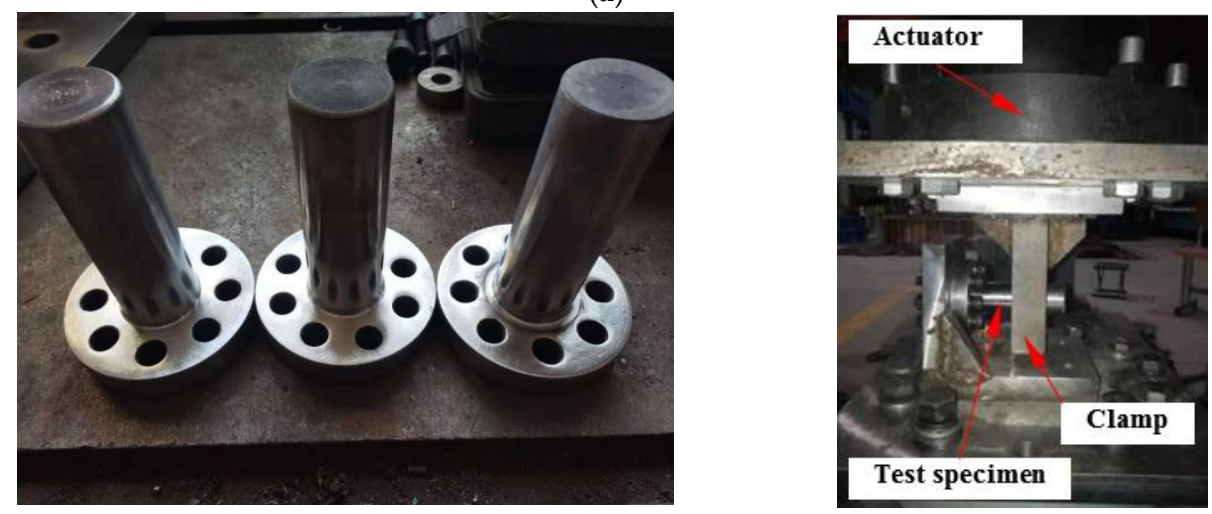

(b)

(c)

Figure 2. Test specimens and test site layout. (a) Test specimen size (unit: mm), (b) Test specimens, (c) Test site layout.

\subsection{Fatigue Failure}

Crack locations and propagation are shown in Figure 3. T1, T2, and T3 cracked at the junction between the shaft and the flange. They propagated in radial and axial directions. This caused connection failure between the shaft and the flange. It was about $10^{\circ}$ between the failure surface of the three specimens and the flange surface, but the angle between the initial crack surface and the flange surface is uncertain. The initial crack was approximately semi-elliptical or semi-circular. The chamfered surface between the vertical flange and the shaft was set to $0^{\circ}$, as shown in Figure 4 . When biasing towards the shaft, the value was positive and when biasing towards the flange, the value was negative. According to measurement and calculation, the maximum normal angle between the initial crack area and the flange surface was about $18^{\circ}$ and the minimum normal angle was about $-8^{\circ}$.

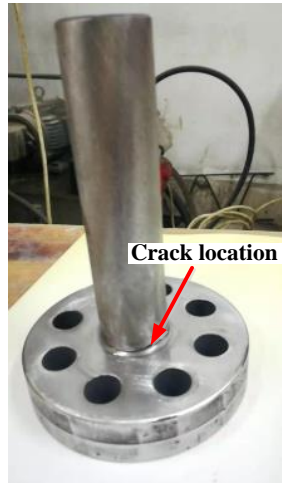

(a)

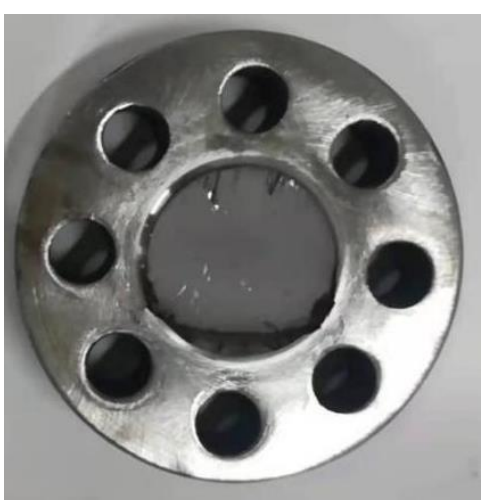

(b)

Figure 3. Crack location and propagation. (a) Crack location, (b) Crack propagation. 


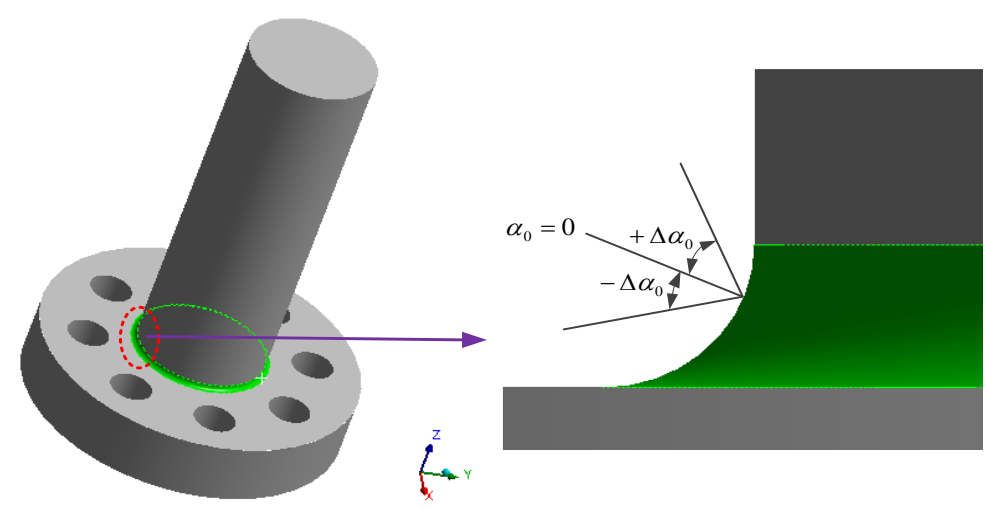

Figure 4. The definition for the initial crack angle.

\subsection{Verification of Numerical Simulation Method for Fatigue Crack}

\subsubsection{Verification of Standard Test}

The stress intensity factor is a key parameter to calculate crack propagation. Compact tension and shear (CTS) samples selected in the literature [33] were used as validation examples to verify the effectiveness of the numerical algorithm in this paper. The specimen dimension and experimental devices are shown in Figure 5. The specimen has a dimension of $70 \mathrm{~mm} \times 90 \mathrm{~mm}$ and a thickness of $14 \mathrm{~mm}$. A total of 6 holes having a diameter of $9.5 \mathrm{~mm}$ were drilled for tension. The initial fracture length was $35 \mathrm{~mm}$. As shown in Figure 5c, the $3 \mathrm{rd}, 4 \mathrm{th}, 5$ th holes were used in the test, yielding three different angles between tension direction and fracture direction of $63^{\circ}, 50^{\circ}, 36^{\circ}$, respectively. The tension loadings are shown in Table 1.

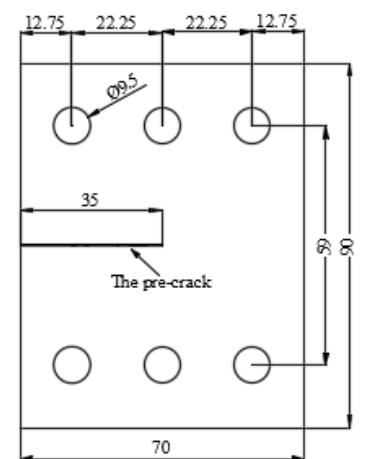

(a)

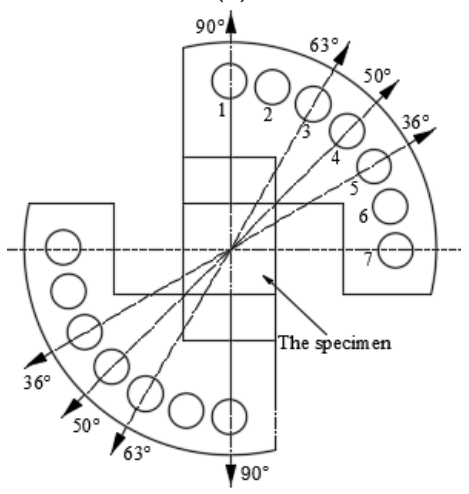

(c)

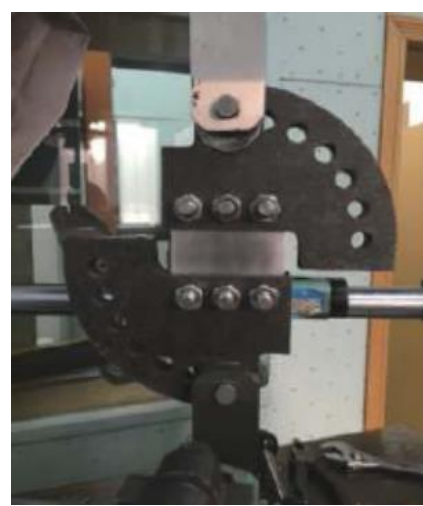

(b)

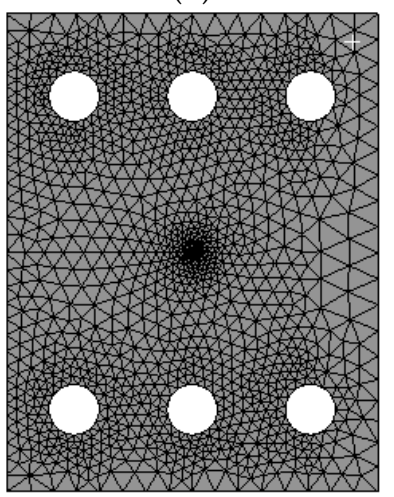

(d)

Figure 5. Compact tension and shear test. (a) Test specimen, (b) Experimental devices [33], (c) Test loading direction, (d) Finite element model. 
Table 1. The tension loadings.

\begin{tabular}{cccc}
\hline Loading Angle $\left(^{\circ}\right)$ & 63 & 50 & 36 \\
\hline Load $\boldsymbol{F}(\mathbf{k N})$ & 8 & 9.6 & 11 \\
\hline
\end{tabular}

For CTS specimens without crack propagation, Richard deducted the approximate analytic formula of the stress intensity factor when the specimens' a/w was between 0.45 and 0.7 , as can be shown [34]:

$$
\begin{gathered}
K_{\mathrm{I}}=\frac{F}{W B} \sqrt{\pi a} \frac{\cos \alpha}{\left(1-\frac{a}{W}\right)} \sqrt{\frac{0.26+2.65\left(\frac{a}{W-a}\right)}{1+0.55\left(\frac{a}{W-a}\right)+0.08\left(\frac{a}{W-a}\right)^{2}}} \\
K_{\mathrm{II}}=\frac{F}{W B} \sqrt{\pi a} \frac{\sin \alpha}{\left(1-\frac{a}{W}\right)} \sqrt{\frac{-0.23+1.40\left(\frac{a}{W-a}\right)}{1-0.67\left(\frac{a}{W-a}\right)+2.08\left(\frac{a}{W-a}\right)^{2}}}
\end{gathered}
$$

where $F$ denoted the loading force, $W$ represented the width of CTS, $B$ was the depth of CTS, $a$ meant crack length, and $\alpha$ was the angle between the loading line and normal direction of the crack surface.

The analytical solution and finite element numerical simulation results of stress intensity factors under different loading angles were shown in Table 2. As can be seen from the comparison results, the error between the stress intensity factor calculated by the numerical calculation method in this paper and Richard's analytical solution was within $\pm 6 \%$. It can be concluded that the numerical method presented in this paper can accurately calculate the stress intensity factor of cracks [35].

Table 2. The comparison between finite element numerical solution and analytical solution of stress

\begin{tabular}{|c|c|c|c|c|c|c|}
\hline \multirow{2}{*}{ Loading Angle $\left({ }^{\circ}\right)$} & \multicolumn{2}{|c|}{$\begin{array}{l}\text { The Calculated Value } \\
\left(\mathrm{MPa} \cdot \mathrm{m}^{0.5}\right)\end{array}$} & \multicolumn{2}{|c|}{$\begin{array}{l}\text { Richard Analytical } \\
\text { Solution (MPa } \mathbf{m}^{0.5} \text { ) }\end{array}$} & \multicolumn{2}{|c|}{ Error (\%) } \\
\hline & $K_{\mathrm{I}}$ & $K_{\text {II }}$ & $K_{\text {II }}$ & $K_{\text {II }}$ & $K_{\text {II }}$ & $K_{\text {II }}$ \\
\hline 36 & 6.10 & 4.01 & 5.85 & 4.20 & 4.3 & -4.5 \\
\hline 50 & 6.49 & 2.75 & 6.64 & 2.91 & -2.3 & -5.5 \\
\hline 63 & 6.29 & 1.61 & 6.45 & 1.71 & -2.5 & -5.9 \\
\hline
\end{tabular}
intensity factor.

\subsubsection{Verification of Test in This Paper}

The numerical analysis was performed on the ANSYS platform. The mesh size and number significantly affected the simulation results. Based on [36,37], we performed a series of simulations to determine the optimal mesh size and number. The SOLID187 element was used to simulate the irregular shape of flange shafts. A total of five cases by varying mesh sizes were simulated as shown in Table 3. Cases 1 and 2 used globally densified mesh with mesh sizes of $3 \mathrm{~mm}$ and $2 \mathrm{~mm}$, respectively. In cases 3,4 , and 5, mesh sizes at the connection of flange face and axle were set as $1.75 \mathrm{~mm}, 1.4 \mathrm{~mm}$, and $1 \mathrm{~mm}$, respectively, and the mesh sizes at other parts were set as $5 \mathrm{~mm}$. The simulation results of five cases are compared in Table 3. The locally densified mesh with a size of $1 \mathrm{~mm}$ (case 5) yielded acceptable simulation accuracy and speed, which is used in this study. 
Table 3. Finite element grid verification results.

\begin{tabular}{|c|c|c|c|c|c|}
\hline \multirow{2}{*}{$\begin{array}{l}\text { Simulation } \\
\text { Response }\end{array}$} & \multicolumn{2}{|c|}{ Integral Uniform Grid } & \multicolumn{3}{|c|}{ Local Grid Refinement } \\
\hline & Case $1(3 \mathrm{~mm})$ & Case $2(2 \mathrm{~mm})$ & Case $3(1.75 \mathrm{~mm})$ & Case $4(1.4 \mathrm{~mm})$ & Case $5(1 \mathrm{~mm})$ \\
\hline \multicolumn{6}{|l|}{ Configuration } \\
\hline Elements & 100,041 & 316,514 & 59,476 & 106,390 & 212,872 \\
\hline Simulation time (h) & 5.6 & 27.5 & 3.7 & 6.1 & 15.3 \\
\hline $\begin{array}{l}\text { Computed result } \\
\text { (cycle number) }\end{array}$ & $9.76 \times 10^{5}$ & $4.72 \times 10^{6}$ & $5.16 \times 10^{6}$ & $6.51 \times 10^{6}$ & $6.56 \times 10^{6}$ \\
\hline
\end{tabular}

Figures 6 and 7 show the evolutions of Von Mises stress and maximum principal stress. It is evident that the Von Mises stress and maximum principal stress at the tips of fractures increases.

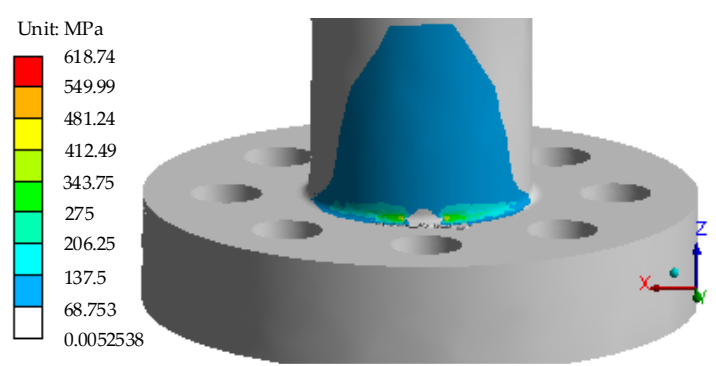

(a)

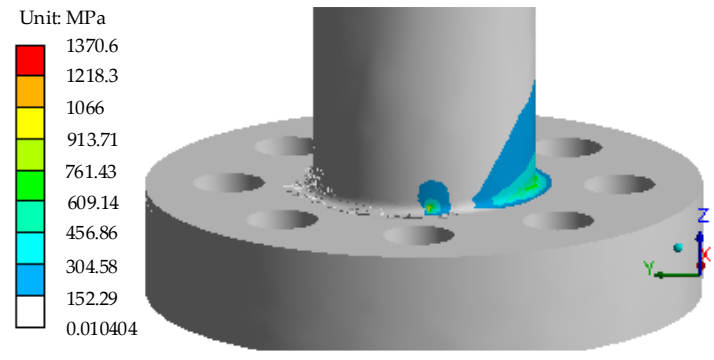

(c)

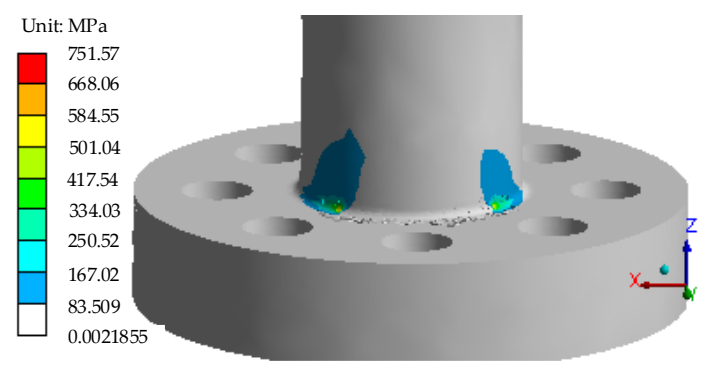

(b)

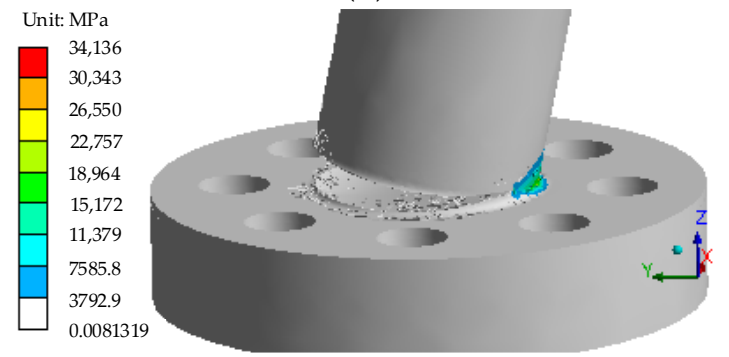

(d)

Figure 6. Evolutions of Von Mises stress during crack propagation (Unit: MPa). (a) Crack depth $a=1 \mathrm{~mm}$, (b) Crack depth $a=10 \mathrm{~mm}$, (c) Crack depth $a=25 \mathrm{~mm},($ d) Crack depth $a=38 \mathrm{~mm}$.

The propagation path and shape changes of the cracks were compared and shown in Figure 8. In the beginning, the fractures grew in the predefined direction. Then, the fracture growing path became parallel with the flange face after the fracture depth reached $3 \mathrm{~mm}$. The fracture growing path deviated from the flange face by a small angle after the fracture depth reached $15 \mathrm{~mm}$ and caused the breakage of the flange shaft eventually. As shown in Figure 8, the numerical results matched experimental results, indicating the effectiveness of the method developed by this paper for predicting the fracture initiation and propagation of the flange shaft. 


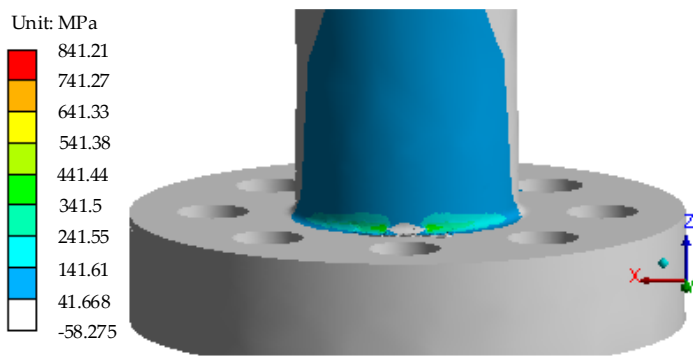

(a)

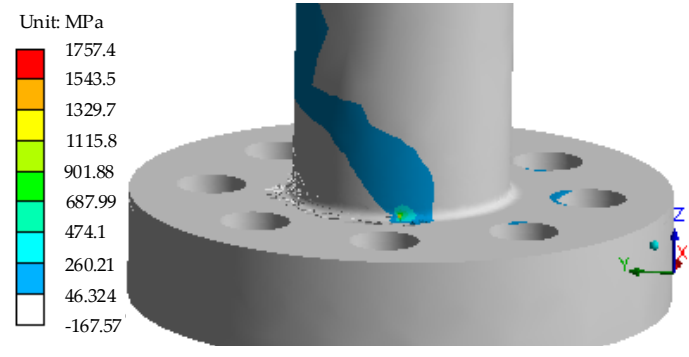

(c)

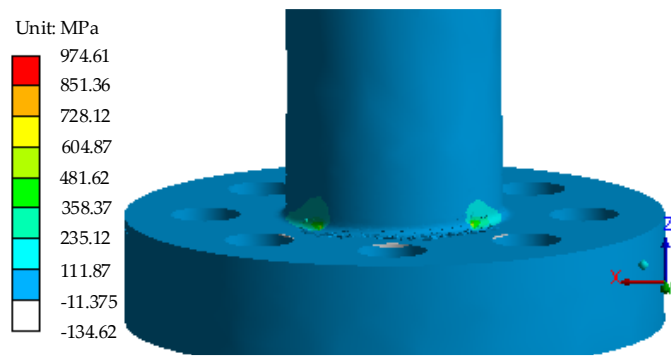

(b)

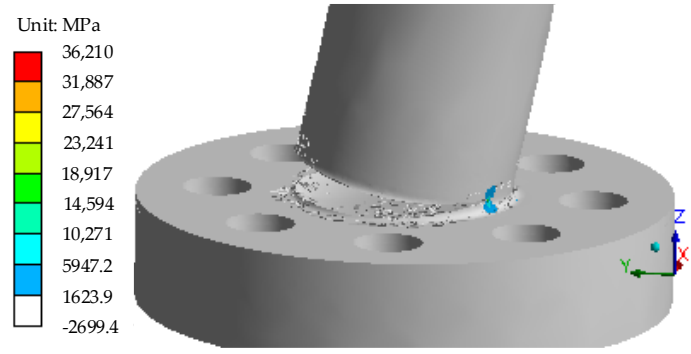

(d)

Figure 7. Evolutions of maximum principal stress during crack propagation (Unit: MPa). (a) Crack depth $a=1 \mathrm{~mm}$, (b) Crack depth $a=10 \mathrm{~mm}$, (c) Crack depth $a=25 \mathrm{~mm}$, (d) Crack depth $a=38 \mathrm{~mm}$.

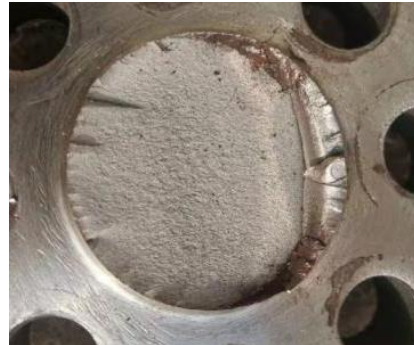

(a)

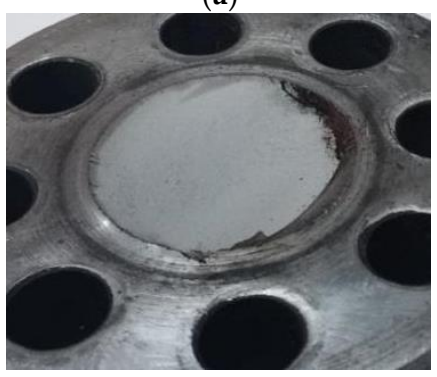

(c)

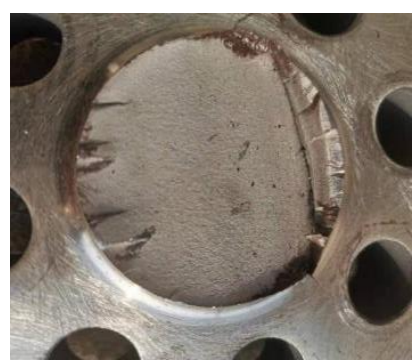

(b)

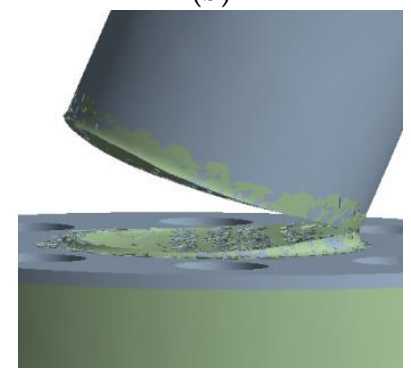

(d)

Figure 8. Comparison between numerical and experimental results. (a) Fracture surface of T1, (b) Fracture surface of T2, (c) Fracture surface of T3, (d) Numerical simulation results.

As can be seen from Figure 8, the numerical simulation method in this paper can reasonably simulate the crack propagation path and morphology change characteristics. Figure 9 shows the $a-N$ curve of the flange shaft's crack propagation calculated by the numerical simulation method, where $a$ was the projection depth of the deepest point of the crack front on the cross-section, the fatigue life of the flange shaft was $6.56 \times 10^{6}$. Table 4 shows the comparison between the simulation values and the test results of the fatigue life of the flange shaft. The average value of the test results of the three groups was $7.16 \times 10^{6}$, and the numerical solution in this paper was $6.56 \times 10^{6}$. The error between the numerical solution and the test value was $8.4 \%$, which meets the requirements of 
engineering applications. Therefore, the numerical simulation method proposed in this paper can be used to analyze the crack propagation characteristics of the flange shaft.

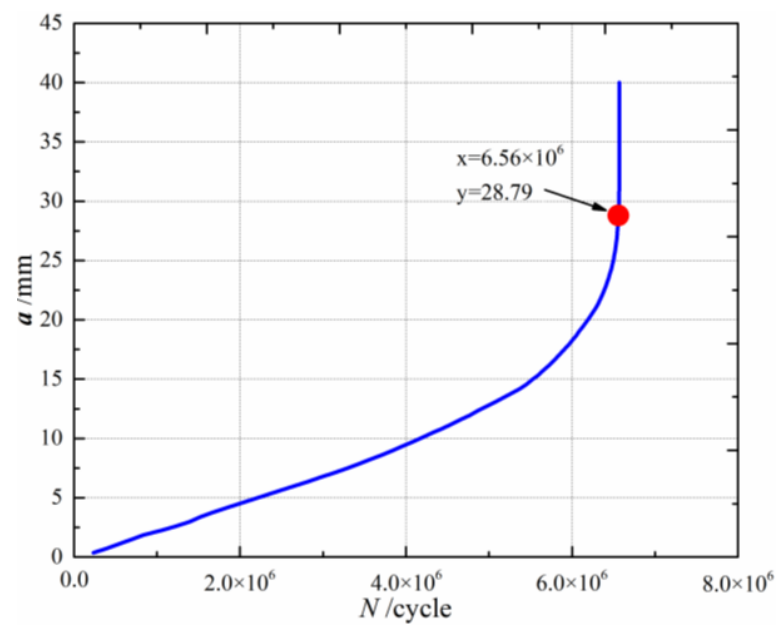

Figure 9. The $a-N$ curve of the flange shaft's crack propagation.

Table 4. The comparison between the simulation values and the test results of the fatigue life of the flange shaft.

\begin{tabular}{|c|c|c|c|c|c|}
\hline \multicolumn{4}{|c|}{ Experiment Results } & \multirow{2}{*}{ Numerical Result } & \multirow{2}{*}{ Error $(\%)$} \\
\hline T1 & T2 & T3 & Average Value & & \\
\hline $6.49 \times 10^{6}$ & $7.36 \times 10^{6}$ & $7.64 \times 10^{6}$ & $7.16 \times 10^{6}$ & $6.56 \times 10^{6}$ & 8.4 \\
\hline
\end{tabular}

\section{The Numerical Simulation of Crack Propagation on the Flange Shaft}

\subsection{Numerical Model}

ANSYS was utilized for modeling based on the actual size of test specimens, with the element type of Solid187. Figure 10 showed the global finite element model and sub-models of the flange shaft. The initial crack was inserted into the chamfer surface between the shaft and the flange, and the element ring grids at the crack front were divided into three-layer symmetric element rings to ensure accuracy. The location of the inserted initial crack and the division of element ring grids at the crack front are shown in Figure 10c. The 15-node wedge element was used in the innermost circle of the element ring; the 20-node hexahedral element was adopted in the middle layer; the 13-node pyramid element was applied in the transition region of the crack tip and global finite element model, and the 10-node tetrahedral element was taken for the global model outside the element ring. There were approximately 18,519 elements in the initial state. Boundary conditions applied on the simulation are almost the same as those in the experiment, with bolt holes being fixed. A concentration force is performed in the cantilever terminal as shown in Figure 10a. To obtain the bottom limited solution of the plasticity deformation, a trial force is applied for probing the plasticity deformation commence in the structure. When the loading value was $11 \mathrm{KN}$, the maximal stress arose up in the neck of the cantilever welding zone, being $382.2 \mathrm{Mpa}$ and approaching the plasticity yield strength that is $386 \mathrm{Mpa}$. The most unfavorable load amplitude was $0.55-11 \mathrm{kN}$. It was selected for loading in the elastic stage, with the stress ratio $R=0.05$. 


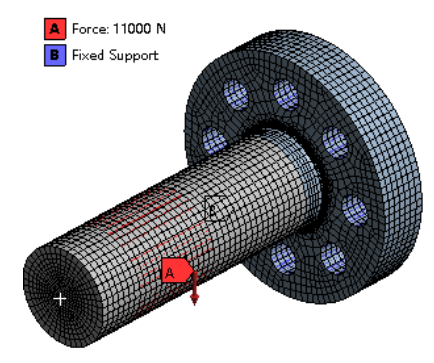

(a)

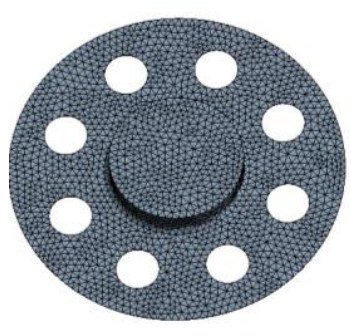

(b)

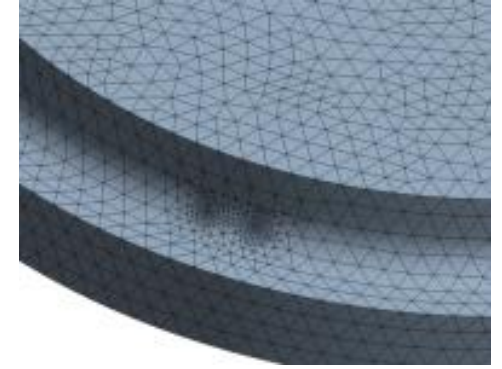

(c)

Figure 10. Analysis technique for the sub-models of flange shaft. (a) Global finite element model with initial crack, (b) Sub-model, (c) Sub-model inserted with initial crack.

\subsection{Geometric Parameters of Initial Crack}

According to the test results and the literature [1,28], the depth of semi-elliptical initial crack was generally not more than $0.5 \mathrm{~mm}$, which can be used as the initial crack depth to reflect the most unfavorable condition. Figure 11 shows a typical semi-elliptical crack on the surface of the cylinder, point A, F, and G located the leading edge of the semi-elliptical crack front, $c$ represented half of the long axis of the ellipse, $a$ represented half of the short axis, and $a$ represented the crack depth in Figure 11. The geometric parameters of the initial crack were shown in Table 5, where $\omega=a_{0} /\left(2 c_{0}\right)$ was defined as the shape ratio of the initial crack, the shape of the elliptical initial crack can be changed by the value of $\omega$. To investigate the effect of initial crack shape ratio on the crack propagation of flange shaft, five groups of initial cracks as shown in Table 5 were selected to simulate the crack propagation of flange shaft specimens, and the initial crack angle effect of fatigue crack propagation of flange shaft was mainly investigated. The definition of the initial crack angle can be obtained from Figure 4 . The simulation results using five types of geometric parameters of initial crack are shown in Figure 12.

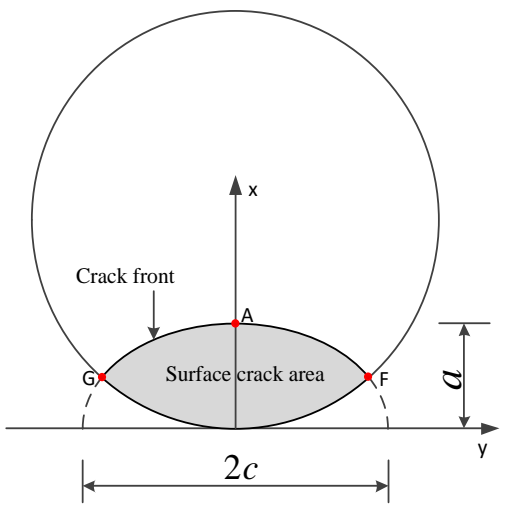

Figure 11. Semi-elliptical crack on the surface of the cylinder.

Table 5. Geometric parameters of initial crack.

\begin{tabular}{cccc}
\hline \multirow{2}{*}{ Numerical Test Number } & \multicolumn{3}{c}{ Geometry Parameters } \\
\cline { 2 - 4 } & $\boldsymbol{a}_{\mathbf{0}} \mathbf{( \mathbf { m m } )}$ & $\boldsymbol{c}_{\mathbf{0}}(\mathbf{m m})$ & $\boldsymbol{\omega}$ \\
\hline $\mathrm{C} 1$ & 0.5 & 2.5 & 0.1 \\
$\mathrm{C} 2$ & 0.5 & 1.0 & 0.25 \\
$\mathrm{C} 3$ & 0.5 & 0.5 & 0.5 \\
$\mathrm{C} 4$ & 0.5 & 0.335 & 0.75 \\
$\mathrm{C} 5$ & 0.5 & 0.25 & 1.0 \\
\hline
\end{tabular}




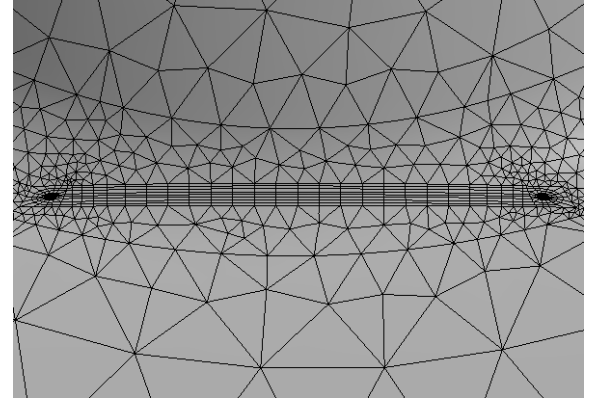

(a)

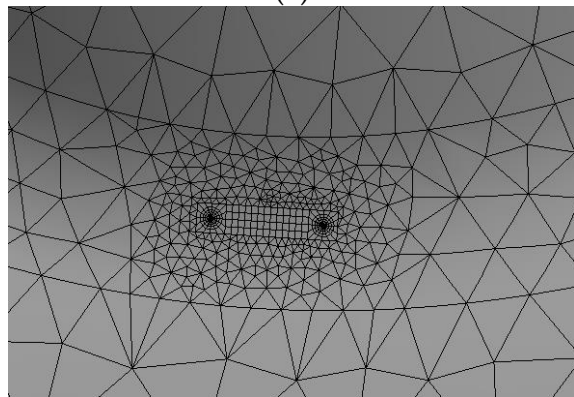

(c)

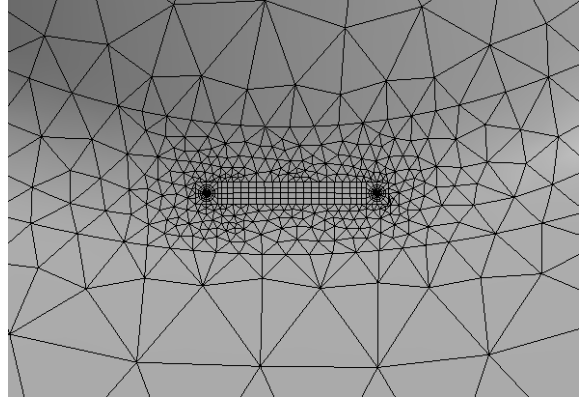

(b)

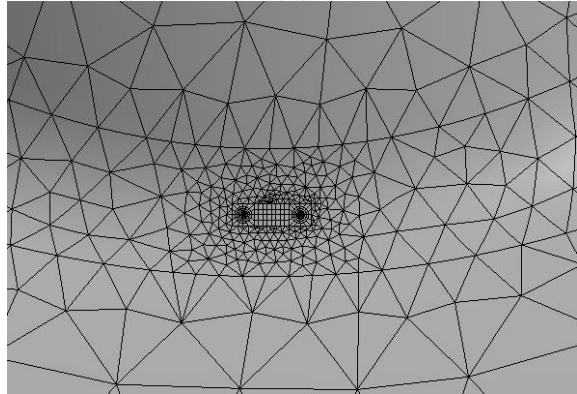

(d)

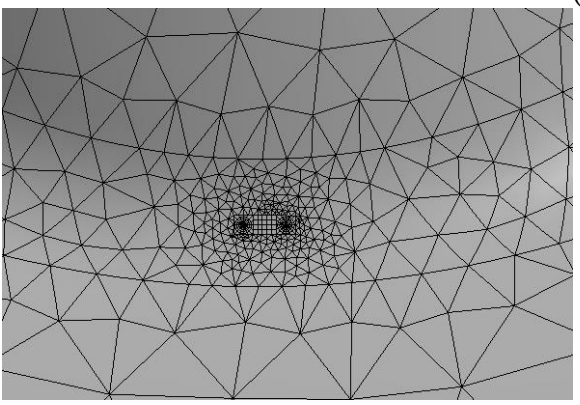

(e)

Figure 12. Five types of calculation grids of initial crack. (a) $\mathrm{C} 1,(\mathbf{b}) \mathrm{C} 2,(\mathbf{c}) \mathrm{C} 3,(\mathbf{d}) \mathrm{C} 4,(\mathbf{e}) \mathrm{C} 5$.

\section{Crack Propagation Characteristics}

\subsection{Description of Calculation Points at the Crack Front}

The calculation points of the crack front were shown in Figure 13, points A, B, C, D, E, $\mathrm{F}$, and $\mathrm{G}$ were taken as the calculation points. If angle $\mathrm{AOF}$ was equal to $\theta$, then points $\mathrm{B}$, $\mathrm{C}, \mathrm{D}$, and $\mathrm{E}$ divided $\theta$ equally into five parts. As the point $\mathrm{F}$ on the surface and its nearby small regions did not satisfy the plane strain hypothesis, the calculation results may have errors. More accurate results can be extrapolated by the calculated values of the intensity factor of the inner point, as recommended in the stress intensity factors handbook [38].

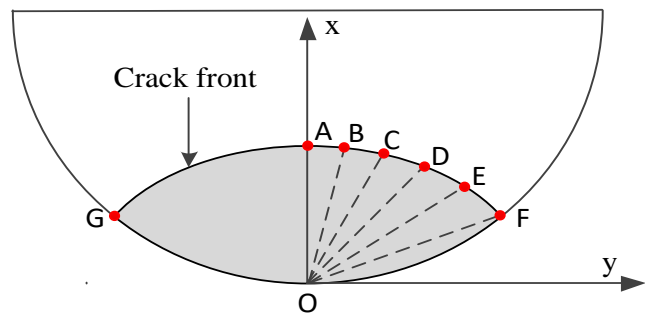

Figure 13. Calculation points at the crack front. 


\subsection{Impact of Different Angles of the Initial Crack on Fatigue Life}

\subsubsection{Test Phenomena}

When the remaining cross-section of the test specimen cannot withstand the external loads (when the stress of the remaining cross-section reached or exceeded the static strength of the material), the crack instability propagation will appear, resulting in an abrupt fracture of the remaining cross-section. The fracture of the test specimen is shown in Figure 14. As can be seen from Figure 14, there was an obvious abrupt fracture area in the fracture, which was rough and significantly different from the fatigue striation. The average width of the fatigue striation accounted for $25-35 \%$ of the total fracture width. As can be seen from Figure 6 above, when crack depth A is $28.79 \mathrm{~mm}$, the flange shaft enters the crack instability propagation. The width of the transient fracture zone is $11.21 \mathrm{~mm}$, about $28 \%$ of the total width, which is in good agreement with the size of the transient fracture zone of the specimen.

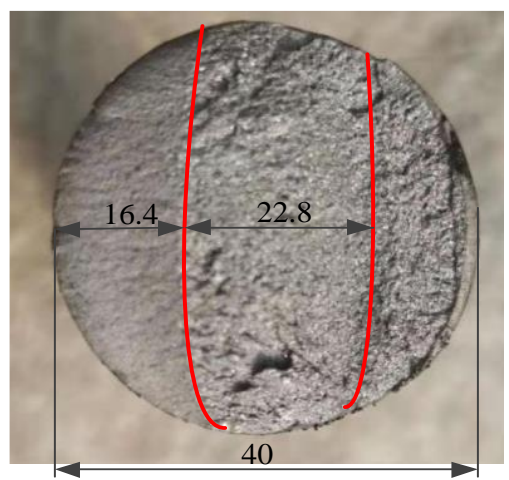

Figure 14. The fracture morphology of the test specimen (unit: $\mathrm{mm}$ ).

Under different initial angles, the propagation of $\mathrm{C} 3$, the semi-circular initial crack, was calculated. The crack propagation was measured by the normalized crack depth $D=a / d$, where $a$ was the projected depth of the deepest point at the crack front on the shaft crosssection, and $d$ was the shaft diameter. To avoid the interference of surface point calculation error in the process of crack propagation, points $\mathrm{A}$ and $\mathrm{E}$ of the crack front were selected to analyze. The changes in the amplitude of the effective stress intensity factor $\Delta K_{\text {eff }}$ of C3 with different initial crack angles were shown in Figure 15. C3 had a similar overall propagation trend of effective stress intensity factor under different initial crack angles. When $D$ was between $0.5-0.6$, the dispersion of the effective stress intensity factor occurred. This indicated that C3's instability propagation was based on the shape of fatigue striation. When $D$ was between $0.6-0.7$, the dispersion of the effective stress intensity factor increased significantly and the propagation simulation ended around $D=0.7$. The simulation results were consistent with the fracture characteristics of test specimens. The normalized crack depths of $\mathrm{C} 3$ with different initial angles were the same when reaching instability, regardless of the initial angle. This showed that the crack instability and the abrupt fracture of the remaining cross-section depended on whether it can withstand the external loads. Based on changes in the amplitude of the effective stress intensity factor, the crack propagation in the length direction was the main cause for the subsequent reduction in the remaining cross-section. 


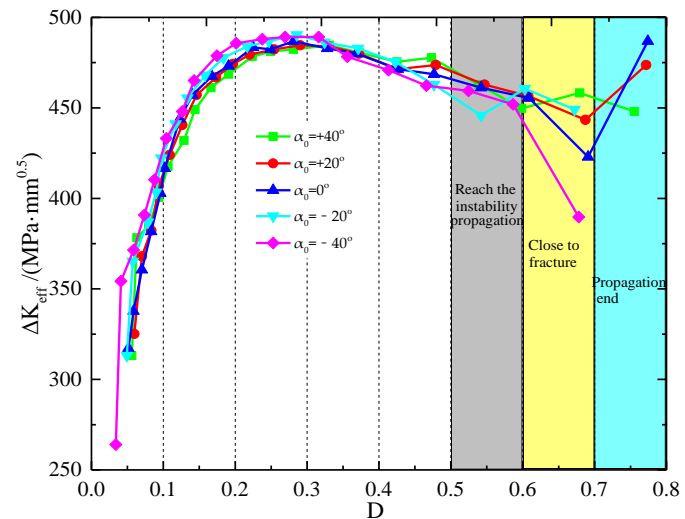

(a)

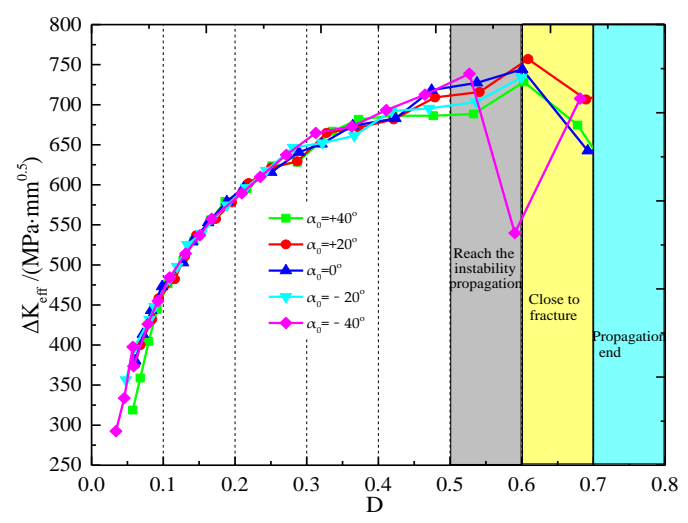

(b)

Figure 15. Changes in the amplitude of effective stress intensity factor. (a) Crack front point A, (b) Crack front point E.

\subsubsection{The Impact of the Initial Crack Angle on Fatigue Life}

The propagation rate of the deepest point A in Figure 16 can be divided into three stages: rapid growth (stage 1), steady decline (stage 2, buffer stage), and instability (stage 3 ). According to the results, $T=0.35$ was regarded as the normalized crack depth when the crack reached the instability, and the corresponding fatigue life was recorded as the full life $N$ of stage 1. If $\mathrm{Nu}$ denoted the life of stage 1 , and $N_{\mathrm{s}}$ was the life of stage 2, then $N=N_{\mathrm{u}}$ $+N_{\mathrm{s}}$. Table 6 showed changes in the propagation rate of the deepest point $\mathrm{A}$, as the number of load cycles increased.

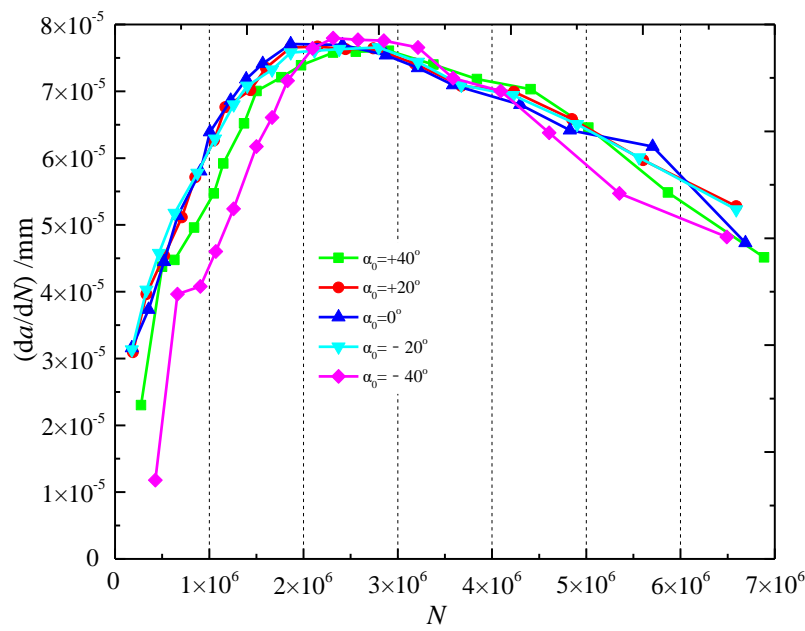

Figure 16. Propagation rate of the deepest point A.

Table 6. Changes of $N_{\mathrm{u}}, N_{\mathrm{s}}$, and the propagation rate under different $\alpha_{0}$.

\begin{tabular}{|c|c|c|c|c|c|c|}
\hline$\alpha_{0} /\left(^{\circ}\right)$ & $\left(N_{\mathrm{u}} / N\right)(\%)$ & $\begin{array}{l}\text { Propagation } \\
\text { Rate (\%) }\end{array}$ & $\begin{array}{c}\text { Average } \\
\text { Propagation } \\
\text { Rate }(\%)\end{array}$ & $N_{\mathrm{s}} / N(\%)$ & $\begin{array}{c}\text { Propagation } \\
\text { Rate }(\%)\end{array}$ & $\begin{array}{c}\text { Average } \\
\text { Propagation } \\
\text { Rate (\%) }\end{array}$ \\
\hline-40 & 60.3 & +562.1 & & 39.7 & -30.5 & \\
\hline-20 & 57.9 & +144.8 & & 42.1 & -31.7 & \\
\hline 0 & 45.7 & +144.0 & +246 & 54.3 & -38.7 & -34.56 \\
\hline 20 & 60.4 & +148.2 & & 39.6 & -31.2 & \\
\hline 40 & 62.3 & +231.0 & & 37.7 & -40.7 & \\
\hline
\end{tabular}


Figure 16 and Table 6 showed the propagation rate. The effect $\alpha_{0}$ only manifested in the propagation rate of stage 1 . Larger $\left|\alpha_{0}\right|\left(\left|\alpha_{0}\right|\right.$ is taking the absolute value of $\left.\alpha_{0}\right)$ would lead to a smaller initial propagation rate. In stage 1 , the energy exchange between the crack and the outside world was fast, and the surrounding stress was unstable. $\alpha_{0}$ had little impact on the propagation rate of stage 2. As for the fatigue life, larger $\left|\alpha_{0}\right|$ would increase $\mathrm{Nu} / \mathrm{N}$ and decrease $N_{\mathrm{s}} / N$. This suggested that a larger initial crack angle $\left|\alpha_{0}\right|$ would reduce the proportion of buffer stage in the total fatigue life. After stage 1, the initial crack with a larger angle would reach the instability propagation faster, which would cause an abrupt fracture of the cross-section. Therefore, the angle of the initial crack at the junction between the shaft and flange mainly affected its fatigue life distribution. The initial crack with a larger angle would adversely influence the flange shaft's detection cycle, maintenance, and reinforcement. The angle of the initial crack should be fully considered in the study and reasonably set before the propagation test or numerical simulation of prefabricated cracks.

\subsection{Impact of Initial Crack Angle on Crack Propagation}

The initial propagation of crack referred to the change of the initial crack before and after the first load cycle. According to the definition of $\Delta K_{\text {th }}$, which was the crack propagation threshold, this state can be calculated and the result can be used to determine whether the crack can propagate at a given load amplitude. Based on the literature [39], when $\mathrm{R}$ is $0.05, \Delta K_{\mathrm{th}}$ is $212.86 \mathrm{MPa} \cdot \mathrm{mm}^{0.5}$ for $45 \#$ steel, the stress intensity factor of the initial propagation of initial cracks with different $\alpha_{0}$ was calculated at the most unfavorable load amplitude. The results are shown in Figure 17:

(1) With $\alpha_{0 p}$ as the benchmark, $\Delta K_{\mathrm{I}}$ of the crack front decreased with the increase of $\left|\alpha_{0}\right| ; \Delta K_{\mathrm{II}}$ and $\Delta K_{\mathrm{III}}$ increased first and then decreased as $\left|\alpha_{0}\right|$ increased. Both of them were less than $\Delta K_{\mathrm{th}}$. Thus, the propagation of the initial crack at the junction between the shaft and flange resulted from $\Delta K_{\mathrm{I}}>\Delta K_{\mathrm{th}} \cdot \Delta K_{\mathrm{II}}$ and $\Delta K_{\mathrm{III}}$ only affected the propagation angle during the initial propagation. When $\left|\alpha_{0}\right|$ exceeded a certain value, $\Delta K_{\mathrm{I}}, \Delta K_{\mathrm{II}}$ and $\Delta K_{\mathrm{III}}$ were less than $\Delta K_{\mathrm{th}}$ and the propagation of the initial crack was not observed.

(2) The changing trend of $\Delta K_{e f f}$ and $\Delta K_{\mathrm{I}}$ was similar. In other words, $\Delta K_{e f f}$ can reasonably reflect the overall change of stress intensity factors during the crack propagation. However, in cracks with large $\left|\alpha_{0}\right|$ (including welding cracks and other similar surface cracks), $\Delta K_{\text {eff }}>\Delta K_{\text {th }}$ might still be true. $\Delta K_{\mathrm{I}}, \Delta K_{\mathrm{II}}$ and $\Delta K_{\mathrm{III}}$ were smaller than $\Delta K_{\mathrm{th}}$. Therefore, the amplitude of the effective stress intensity factor cannot be used to assess the crack propagation. In relevant studies, crack propagation should be evaluated by three stress intensity factors and the crack propagation threshold.

We used $\left|K_{\mathrm{II}} / K_{\mathrm{I}}\right|$ and $\left|K_{\mathrm{III}} / K_{\mathrm{I}}\right|$ to reflect the size relation among three stress intensity factors and obtained the changing pattern of stress intensity factor on the front of the semi-circular crack C3 with different initial angles. The results are also shown in Figure 17:

(1) The crack was categorized to a mixed I-II-III mode, which was dominated by mode I. At a certain initial angle, it can be considered as the mode I crack. In this example, $\alpha_{0}$ was about $+4^{\circ}$, and its angle was expressed as $\alpha_{0 p}$.

(2) The larger $\alpha_{0}$, the stronger modes II-III characteristics would be. When $\alpha_{0}$ was larger, $K_{\mathrm{II}}$ accounted for a large proportion at both the surface and the deepest point of $\mathrm{C} 3$. The stress difference between positions of the crack front was large, but the crack still belonged to mode I; $K_{\text {III }}$ gradually increased from the deepest point towards the surface. Under the dominant action of $K_{\mathrm{II}}$ and $K_{\mathrm{III}}$, the surface and the deepest point of C3 deflected, as shown in Figure 18. 


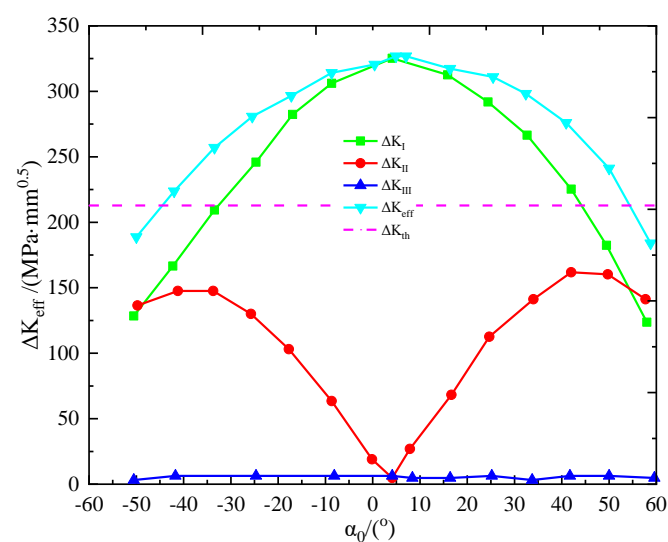

(a)

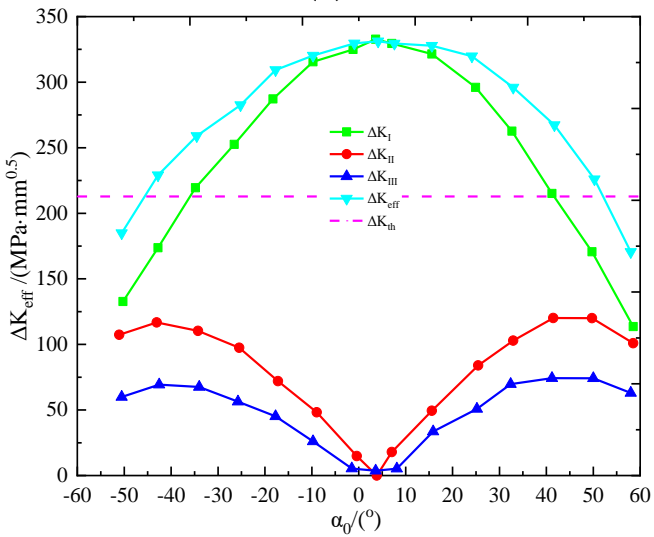

(c)

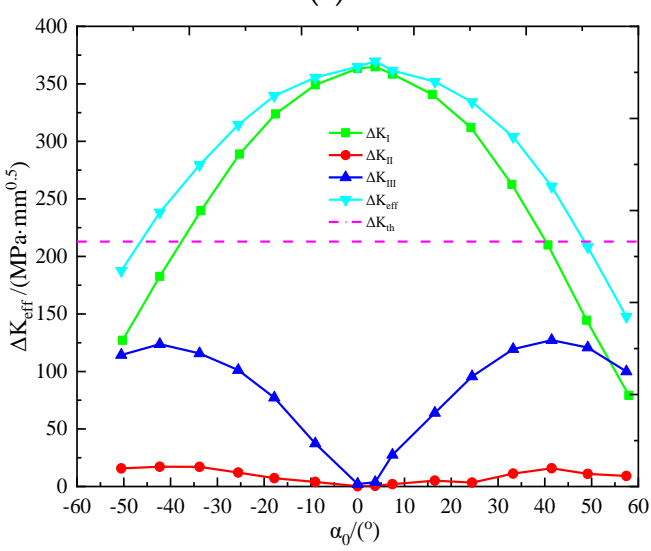

(e)

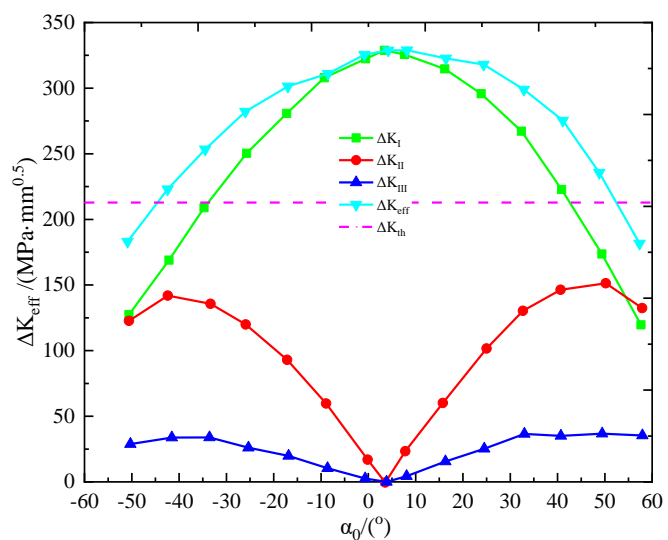

(b)

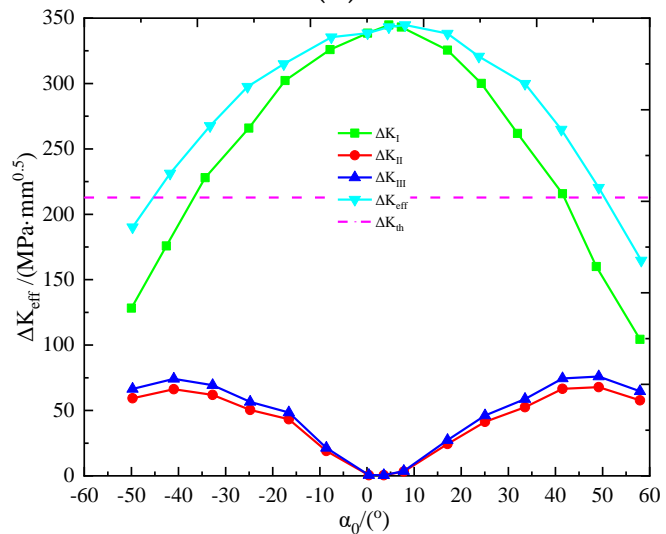

(d)

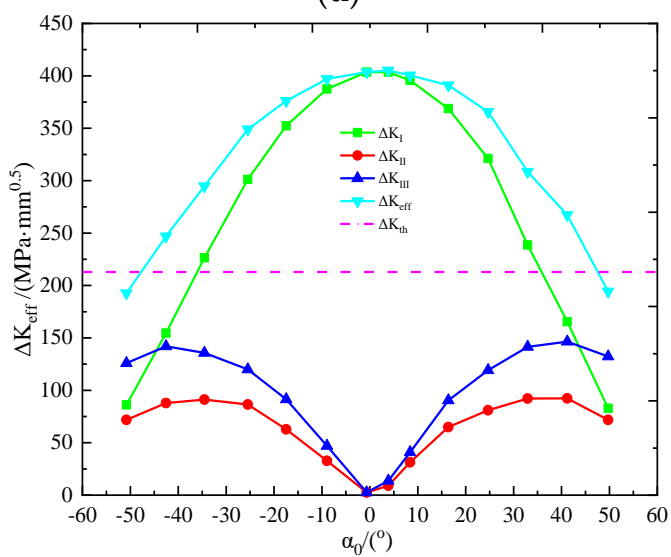

(f)

Figure 17. The stress intensity factor amplitude of the initial propagation state of initial cracks.

(a) Crack front point A, (b) Crack front point B, (c) Crack front point C, (d) Crack front point D,

(e) Crack front point E, (f) Crack front point F. 
(a)

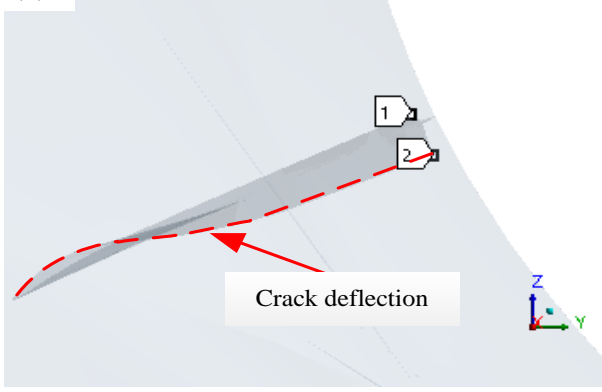

(b)

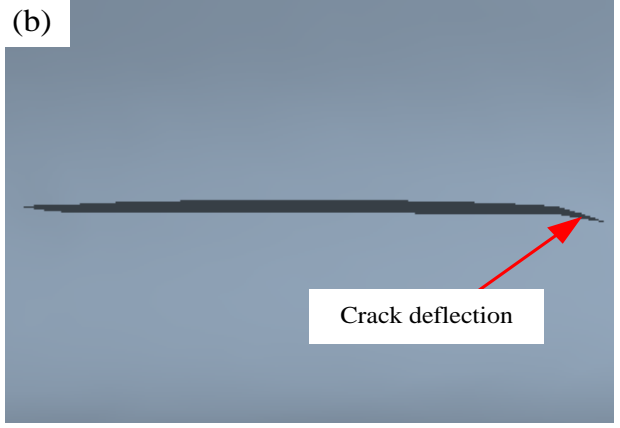

Figure 18. Crack shift during propagation. (a) Deflection under KII dominant action; (b) Deflection under KIII dominant action.

\subsection{Maximum Effective Angle Interval for the Initial Crack Propagation}

Previous studies showed that an initial crack would only propagate under an effective angle interval. This may be affected by the geometric parameters, the stress state of the crack, and the steel type. The influence of crack shape ratio on the effective angle interval of crack propagation of flange shaft will be analyzed as follows.

\subsubsection{Shape Ratio}

To reflect the most unfavorable condition, this paper used $0.5 \mathrm{~mm}$ as the maximum initial crack depth in engineering [1,30]. According to previous studies, $\Delta K_{\mathrm{I}}$ and $\Delta K_{\text {th }}$ were used to judge the propagation of the initial crack at the junction between the shaft and flange. The effective angle interval for the propagation of $\mathrm{C} 1-\mathrm{C} 5$ initial cracks and its relationship with the shape ratio are shown in Figures 19 and 20 and Table 7, respectively:

(1) $\left|\Delta \alpha_{0 c}\right|=\left|\alpha_{0 \max }-\alpha_{0 \min }\right|$ was used to define the effective angle interval for the propagation of initial cracks at the junction between the shaft and flange. $\alpha_{0 \max }$ and $\alpha_{0 \text { min }}$ were the upper and lower limits of the interval's initial angles. Only the initial cracks with an angle within the interval can propagate. The initial cracks with an angle outside the interval did not propagate in the elastic stage. The interval was determined by the size relation between the $\Delta K_{\mathrm{I}}$ of each point at the crack front and the base metal $\Delta K_{\text {th }}$. The $\alpha_{0 p}$ of the initial crack did not change with the shape ratio and $\left|\Delta \alpha_{0 c}\right|$ would decrease as $\omega$ grown under the same stress ratio.

(2) The long flat cracks $(\omega<0.5)$ did not propagate in the direction of the surface length at a certain initial angle. They only propagated locally in the depth direction. The crack propagation towards the surface was smaller than that in the depth direction. The narrow and deep cracks $(\omega>0.5)$ experienced the opposite propagation pattern.

Table 7. The effective angle interval for the propagation of initial cracks with different shape ratios.

\begin{tabular}{ccccc}
\hline Numerical Test Number & $\boldsymbol{a}_{\mathbf{0}} \mathbf{( \mathbf { m m } )}$ & $\boldsymbol{\alpha}_{\mathbf{0} \boldsymbol{p}}\left({ }^{\circ}\right)$ & $\boldsymbol{\omega}$ & $\left.\left|\boldsymbol{\Delta} \boldsymbol{\alpha}_{\mathbf{0} \boldsymbol{c}}\right| \boldsymbol{(}^{\circ}\right)$ \\
\hline $\mathrm{C} 1$ & 0.5 & +4 & 0.1 & 108.9 \\
$\mathrm{C} 2$ & 0.5 & +4 & 0.25 & 100.1 \\
$\mathrm{C} 3$ & 0.5 & +4 & 0.5 & 79.3 \\
$\mathrm{C} 4$ & 0.5 & +4 & 0.75 & 72.9 \\
$\mathrm{C} 5$ & 0.5 & +4 & 1.0 & 68.8 \\
\hline
\end{tabular}




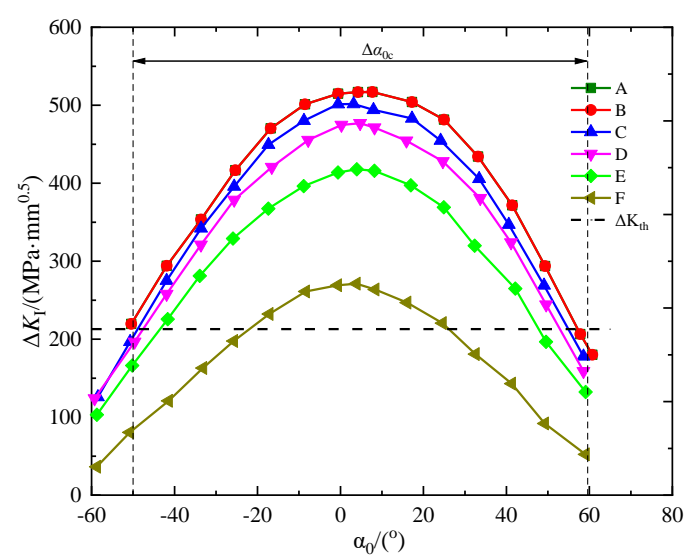

(a)

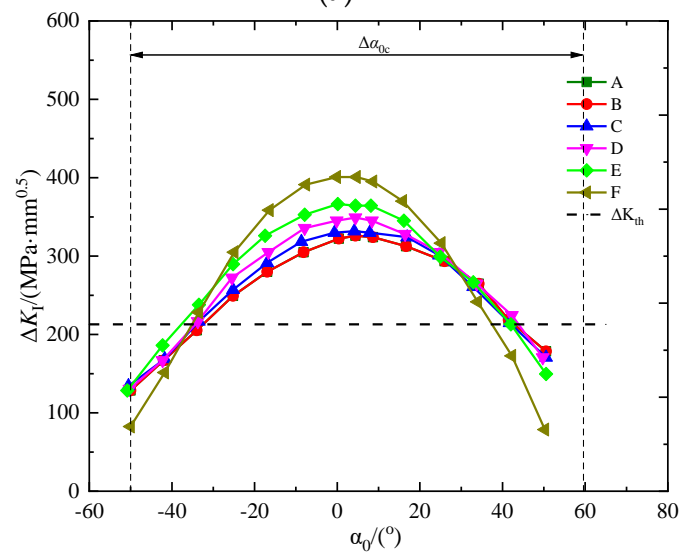

(c)

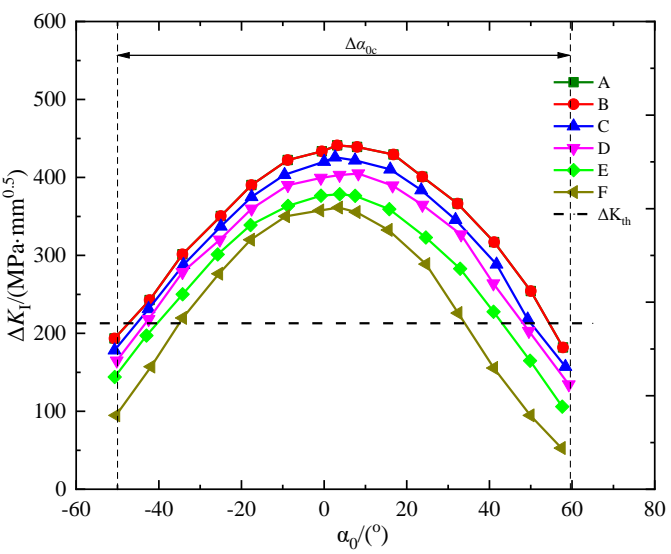

(b)

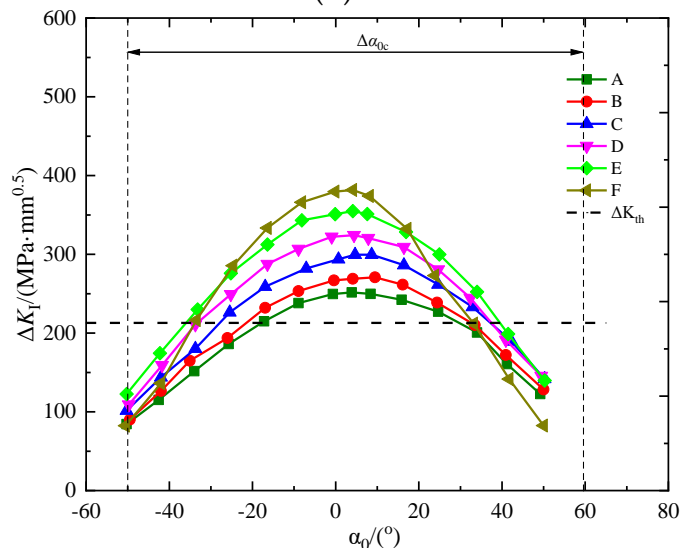

(d)

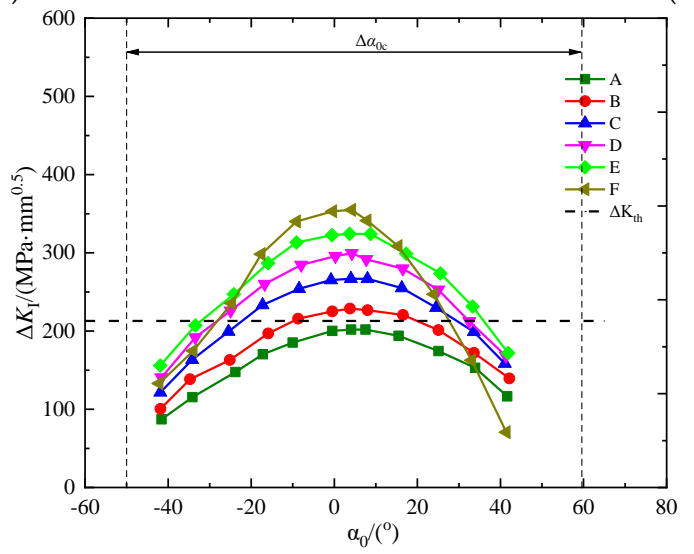

(e)

Figure 19. The effective angle interval for the propagation of initial cracks. (a) The shape ratio $\omega=0.1$, (b) The shape ratio $\omega=0.25$, (c) The shape ratio $\omega=0.5$, (d) The shape ratio $\omega=0.75$, (e) The shape ratio $\omega=1.0$. 


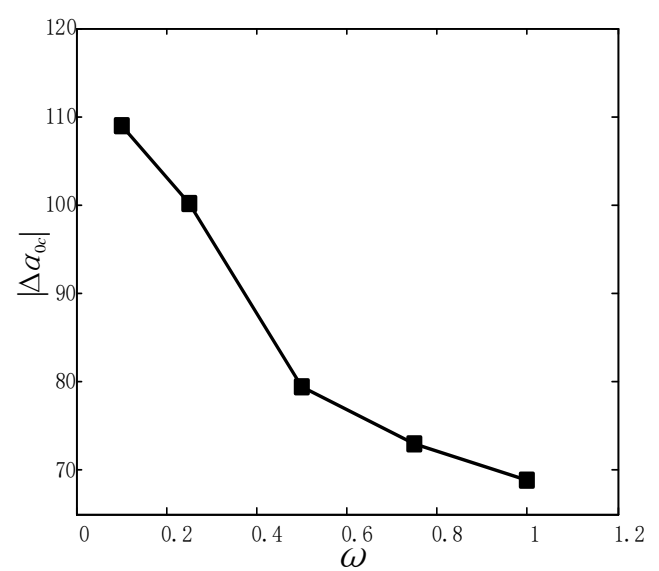

Figure 20. The relationship between the effective angle interval for the propagation of initial cracks and the shape ratio.

\subsubsection{Mathematical Model of Effective Angle Interval}

Changes in the amplitude of stress intensity factor at points $A$ and $E$ with the shape ratio were given in Figure 21. When $\omega<0.5, \Delta K_{\mathrm{I}}$ of point $A$ on the initial cracks with different angles, almost changed linearly with $\omega$; when $\omega>0.5, \Delta K_{\mathrm{I}}$ of point $E$ on the initial cracks with different angles changed linearly with $\omega$. It was assumed that slopes $k_{\mathrm{A}}$ and $k_{\mathrm{E}}$ were constants, which were less than 0 when the load condition was determined, as can be shown in Figure 21. Therefore, $\left|\Delta \alpha_{0 c}\right|$ and $\omega=0.5$ showed a piecewise linear and negative correlation. The general form of fitting formula was obtained by Formula (16):

$$
\left|\Delta \alpha_{0 c}\right|= \begin{cases}k_{1} \omega+b_{1}, & 0<\omega<0.5 \\ k_{2} \omega+b_{2}, & \omega>0.5\end{cases}
$$

where: $k_{1}, b_{1}, k_{2}$, and $b_{2}$ were the constants related to the initial crack $\Delta K_{\mathrm{I}}$ and the crack propagation threshold $\Delta K_{\mathrm{th}}$. Figure 22 shows the fitting results of the effective angle interval for the propagation of the initial crack of $45 \#$ steel flange shaft. Under the most unfavorable stress condition, $k_{1}=-74.94, b_{1}=117.3, k_{2}=-21, b_{2}=89.42$.

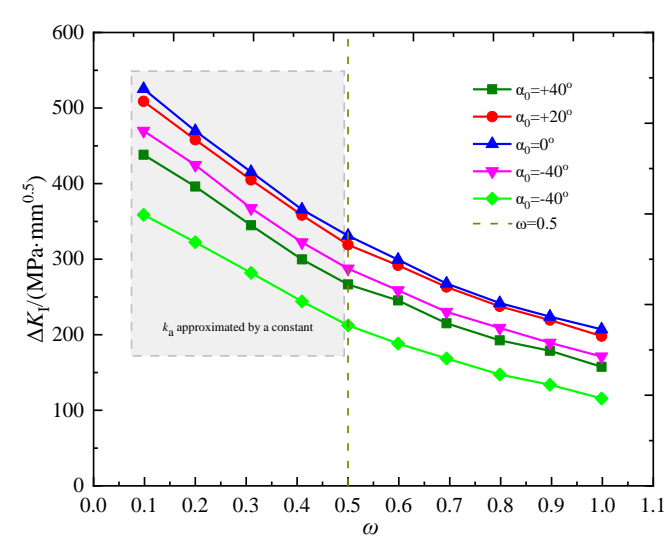

(a)

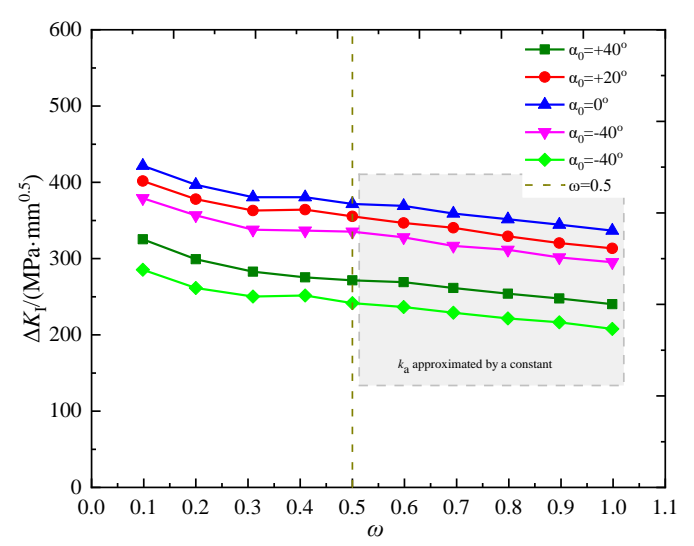

(b)

Figure 21. Changes in the amplitude of stress intensity factor at points $\mathrm{A}$ and $\mathrm{E}$ with the shape ratio. (a) Location of crack front: point A, (b) Location of crack front: point E. 


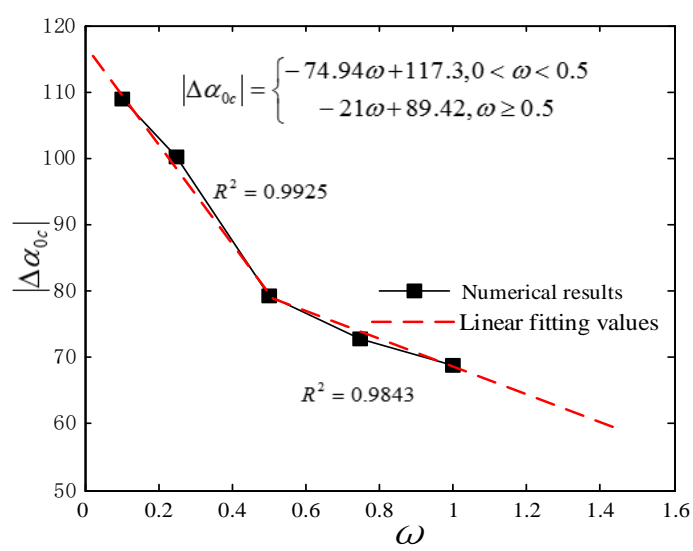

Figure 22. The fitting results of the effective angle interval for the propagation of the initial crack.

Formula (16) was obtained based on the maximum stress amplitude in the elastic stage and the maximum initial crack depth, which was generally accepted in engineering. Under this condition, the results reflected the maximum value of $\left|\Delta \alpha_{0 c}\right| \cdot\left|\Delta \alpha_{0 c}\right|$ for different materials and stress levels can be calculated in the same way. The fitting calculation formula helps researchers comprehensively consider the initial angle and reasonably set it in the crack propagation calculation. It will deepen researchers' understanding of the propagation characteristics of fatigue crack and provide a reasonable reference for the duration of the crack detection cycle. With this knowledge, engineers can formulate related measures for maintenance and reinforcement.

\section{Conclusions}

(1) The initial crack appeared at the junction between the shaft and flange and propagated in radial and axial directions; the instability propagation of the crack caused an abrupt fracture of the cross-section, resulting in connection failure; the angle of the initial crack was uncertain.

(2) The crack was the mixed I-II-III mode dominated by mode I. Cracks with larger initial angles would have stronger mode II-III characteristics; KII and KIII affected the propagation angle of the crack in radial and axial directions as well as the direction of the structure surface.

(3) The propagation of the deepest point A of the crack was at the junction between shaft and flange. It can be divided into three stages: rapid growth (stage 1), steady decline (stage 2, buffer stage), and instability (stage 3). First, the initial crack angle only had a significant effect on the propagation rate of stage 1 . Second, the initial crack angle affected the distribution of the fatigue life upon the structure during the propagation stage. The crack with a larger initial crack angle had a smaller proportion of buffer stage in the total fatigue life. After stage 1, a larger crack initial angle accelerated the structure to reach the instability propagation, which led to an abrupt fracture of the cross-section. This was more unfavorable for deciding how regular the crack detection should be carried out or pushing forward maintenance and reinforcement.

(4) It was the size relation between $\Delta \mathrm{K}_{\mathrm{I}}$ and $\Delta \mathrm{K}_{\mathrm{th}}$ that determined the crack propagation at the junction between the shaft and the flange. The effective stress intensity factor can partly reflect the law of crack propagation, but cannot serve as a criterion for crack propagation. Moreover, crack propagation can be determined by the effective angle interval, which was negatively correlated with the shape ratio.

(5) The initial crack at the junction between the shaft and the flange only propagated at a certain initial angle. There was a piecewise linear negative correlation between the effective angle interval and the shape ratio. The fitting calculation formula can provide the basis for the crack propagation research and can also be used to judge the propagation of welding cracks or other similar surface cracks. This paper has studied the $45 \#$ steel flange and shaft. It obtained the maximum value of effective 
angle interval for the propagation of the initial crack. The formulas for other types of steels and stress levels and the evaluation method based on reliability need to be further explored.

\begin{abstract}
Author Contributions: Z.X.: Investigation, Methodology, Software, Writing-original draft. Y.C.: Data curation, Validation. B.L.: Software, Validation. K.L.: Formal analysis, Writing-review and editing, Funding acquisition. F.S.: Writing-review and editing, Drawing graphs. P.C.: Data curation, Funding acquisition, Project administration, Writing-review and editing. All authors have read and agreed to the published version of the manuscript.
\end{abstract}

Funding: This research was funded by the National Natural Science Foundation of China (grant number 51769028), and the Natural Science Foundation of Shanxi Province (grant No. 2018JQ5019).

Institutional Review Board Statement: Not applicable.

Informed Consent Statement: Not applicable.

Data Availability Statement: The data used to support the findings of this study are available from the corresponding author and upon request.

Conflicts of Interest: The authors declare no conflict of interest.

\title{
References
}

1. $\quad$ Bangchun, W. Mechanical Design Manual; China Machine Press: Beijing, China, 2015.

2. Li, Y.T.; Duan, H.Y.; Wang, R.F. Effect of Notched Parameters on Low Cycle Fatigue Life of Shaft with Annular Notch under Cantilever Bending. Key Eng. Mater. 2011, 462, 136-141. [CrossRef]

3. Asi, O. Fatigue failure of a rear axle shaft of an automobile. Eng. Fail. Anal. 2006, 13, 1293-1302. [CrossRef]

4. Fonseca, L.G.A.; Cantisano, A.; Faria, A.R. Numerical modeling of deep rolling influence over crankshaft bending and correlation with fatigue behavior. Fatigue Fract. Eng. Mater. Struct. 2020, 43, 672-683. [CrossRef]

5. Gardin, C.; Courtin, S.; Bézine, G.; Bertheau, D.; Hamouda, H.B.H. Numerical simulation of fatigue crack propagation in compressive residual stress fields of notched round bars. Fatigue Fract. Eng. Mater. Struct. 2007, 30, 231-242. [CrossRef]

6. Jamil, M.; Khan, A.M.; Hegab, H.; Sarfraz, S.; Sharma, N.; Mia, M.; Gupta, M.K.; Zhao, G.; Moustabchir, H.; Pruncu, C.I. Internal Cracks and Non-Metallic Inclusions as Root Causes of Casting Failure in Sugar Mill Roller Shafts. Materials 2019, 12, 2474. [CrossRef]

7. Ktari, A.; Haddar, N.; Rezai-Aria, F.; Ayedi, H.F. On the assessment of train crankshafts fatigue life based on LCF tests and 2D-FE evaluation of J-integral. Eng. Fail. Anal. 2016, 66, 354-364. [CrossRef]

8. Atanasovska, I.; Jelić, M.; Mitrović, R.; Momčilović, D. The Influence of Corrosion on Stress Concentration Factor at Shaft to Flange Radius, Power Transmissions; Springer: Berlin/Heidelberg, Germany, 2013; pp. 657-666.

9. Li, J.; Zhang, P.; Lu, L.; Lv, F.; Miao, X.-T.; Chang, L.; Zhou, B.-B.; He, X.-H.; Zhou, C.-Y. Effect of pre-strain on fatigue crack growth behavior for commercial pure titanium at ambient temperature. Int. J. Fatigue 2018, 117, 27-38. [CrossRef]

10. Sola, J.F.; Alinejad, F.; Rahimidehgolan, F.; Niazmand, A. Fatigue life assessment of crankshaft with increased horsepower. Int. J. Struct. Integr. 2019, 10, 13-24. [CrossRef]

11. Pandey, R. Failure of diesel-engine crankshafts. Eng. Fail. Anal. 2003, 10, 165-175. [CrossRef]

12. Lei, X. Dynamic Modeling of Vibration and Analysis on Crack Fault in I.C.E. Crankshafts. Ph.D. Thesis, Dalian University of Technology, Dalian, China, 2003.

13. Zhou, X. Theoretical and Experimental Study on Fatigue Behavior and Reliability of Engine Crankshaft. Ph.D. Thesis, Zhejiang University, Hangzhou, China, 2006.

14. Yang, F.-P.; Chen, T.; Lu, Y.-C. The Effects of Carburization on the Fatigue Crack Growth Behaviors of Local Surface Cracks in Cylindrical Bars. J. Mater. Eng. Perform. 2019, 28, 3423-3429. [CrossRef]

15. Ye, Z.-Y.; Liu, D.-X.; Zhang, X.-H.; Zhang, X.-M.; Lei, M.-X.; Yang, Z. Corrosion Fatigue Behavior of 7A85 Aluminum Alloy Thick Plate in $\mathrm{NaCl}$ Solution. Acta Met. Sin. (Engl. Lett.) 2015, 28, 1047-1054. [CrossRef]

16. Fonte, M.; Anes, V.; Duarte, P.; Reis, L.; Freitas, M. Crankshaft failure analysis of a boxer diesel motor. Eng. Fail. Anal. 2015, 56, 109-115. [CrossRef]

17. Fonte, M.; Freitas, M. Semi-elliptical fatigue crack growth under rotating or reversed bending combined with steady torsion. Fatigue Fract. Eng. Mater. Struct. 1997, 20, 895-906. [CrossRef]

18. Fonte, M.; Freitas, M.; Reis, L. Failure analysis of a damaged diesel motor crankshaft. Eng. Fail. Anal. 2019, 102, 1-6. [CrossRef]

19. Yang, F.-P.; Kuang, Z.-B. Fatigue crack growth for a surface crack in a round bar under multi-axial loading condition. Fatigue Fract. Eng. Mater. Struct. 2005, 28, 963-970. [CrossRef]

20. Zangeneh, S.; Ketabchi, M.; Kalaki, A. Fracture failure analysis of AISI 304L stainless steel shaft. Eng. Fail. Anal. 2014, 36, 155-165. [CrossRef] 
21. Azevedo, T.F.; Sampaio, W.R.V.; Câmara, E.C.B.; Lima, G.D.; dos Santos Silva, W.F.; da Silva Ramos, S. Failure analysis of a sugarcane loader rear shaft. Eng. Fail. Anal. 2019, 109, 104326. [CrossRef]

22. Aliakbari, K.; Nejad, R.M.; Mamaghani, T.A.; Pouryamout, P.; Asiabaraki, H.R. Failure analysis of ductile iron crankshaft in compact pickup truck diesel engine. Structures 2021, 36, 482-492. [CrossRef]

23. Khameneh, M.J.; Azadi, M. Evaluation of high-cycle bending fatigue and fracture behaviors in EN-GJS700-2 ductile cast iron of crankshafts. Eng. Fail. Anal. 2018, 85, 189-200. [CrossRef]

24. Alvarez, P.; Vázquez, L.; Ruiz, N.; Rodríguez, P.; Magaña, A.; Niklas, A.; Santos, F. Comparison of Hot Cracking Susceptibility of TIG and Laser Beam Welded Alloy 718 by Varestraint Testing. Metals 2019, 9, 2075-4701. [CrossRef]

25. Coro, A.; Macareno, L.M.; Aguirrebeitia, J.; De Lacalle, L.N.L. A Methodology to Evaluate the Reliability Impact of the Replacement of Welded Components by Additive Manufacturing Spare Parts. Metals 2019, 9, 932. [CrossRef]

26. Rodriguez, A.; De Lacalle, L.N.L.; Pereira, O.; Fernandez, A.; Ayesta, I. Isotropic finishing of austempered iron casting cylindrical parts by roller burnishing. Int. J. Adv. Manuf. Technol. 2020, 110, 753-761. [CrossRef] [PubMed]

27. Liu, Y.; Lian, Z.; Xia, C.; Qian, L.; Liu, S. Fracture failure analysis and research on drive shaft of positive displacement motor. Eng. Fail. Anal. 2019, 106, 104145. [CrossRef]

28. Erdogan, F.; Sih, G.C. On the crack extension in plates under plane loading and transverse shear. J. Basic Eng. 1963, 85, 519-525. [CrossRef]

29. Yangfan, Q.; Te, C.; Yiming, C.; Fengpeng, Y. Experimental Study on the I-II Mixed Mode Fatigue Crack Growth in Polyethylene. Chin. Q. Mech. 2021, 42, 87-97.

30. British Standards Institution. Guide on Methods for Assessing the Acceptability of flaws in Metallic Structures; British Standards Institution: London, UK, 2013.

31. Paris, P.; Erdogan, F. A Critical Analysis of Crack Propagation Laws. J. Basic Eng. 1963, 85, 528-533. [CrossRef]

32. Ma, S.; Hu, H. The mixed-mode propagation of fatigue crack in CTS specimen. Chin. J. Theor. Appl. Mech. 2006, 38, 698-704.

33. Lianqing, W.; Jin, K.; Hongying, W. Investigation on mixed mode I-II fatigue crack of 7050 aluminum alloy. China Meas. Tes 2021, 47, 139-146.

34. Richard, H.A.; Benitz, K. A loading device for the creation of mixed mode in fracture mechanics. Int. J. Fract. 1983, 22, R55-R58. [CrossRef]

35. Liu, C.; Wu, D.; Li, Y.; Du, Y. Large-scale pavement roughness measurements with vehicle crowdsourced data using semisupervised learning. Transp. Res. Part C Emerg. Technol. 2021, 125, 103048. [CrossRef]

36. Alcázar, J.; Abate, G.; Antunez, N.; Simoncelli, A.; Egea, A.J.S.; Krahmer, D.M.; de Lacalle, N.L. Reduction of Die Wear and Structural Defects of Railway Screw Spike Heads Estimated by FEM. Metals 2021, 11, 1834. [CrossRef]

37. Alshoaibi, A.M.; Fageehi, Y.A. 3D modelling of fatigue crack growth and life predictions using ANSYS. Ain Shams Eng. J. 2021, 13, 101636. [CrossRef]

38. Establishment, C.A. Stress Intensity Factor Handbook (Revised Edition); Science Press: Beijing, China, 1993.

39. Xinhua, Y.; Chuanyao, C. Fatigue and Fracture; Huazhong University of Science and Technology Press: Wuhan, China, 2018. 